\title{
Modern earthquakes as a key to understanding those of the past: the intensity attenuation curve speaks about earthquake depth and magnitude
}

\author{
Paola Sbarra ${ }^{1}$, Pierfrancesco Burrato ${ }^{1}$, Valerio De Rubeis ${ }^{1}$, Patrizia Tosi ${ }^{1}$, Gianluca Valensise ${ }^{1}$, \\ Roberto Vallone ${ }^{1}$, and Paola Vannoli ${ }^{1}$ \\ ${ }^{1}$ Istituto Nazionale di Geofisica e Vulcanologia (INGV), Via di Vigna Murata 605, 00143 Rome (RM), Italy
}

Correspondence: Paola Sbarra (paola.sbarra@ingv.it)

\begin{abstract}
The Italian historical earthquake record is among the richest worldwide; as such it allows the development of advanced techniques for retrieving quantitative information by calibration with recent earthquakes. Building on a pilot elaboration of northern Italy earthquakes, we developed a procedure for determining the focal depth of all Italian earthquakes from intensity data alone. In a second step the procedure calculates their magnitude, taking into account the inferred depth.

Focal depth exhibits a substantial variability countrywide, but so far received little attention: pre-instrumental earthquakes were routinely "flattened" at upper crustal level $(\sim 10 \mathrm{~km})$, on the grounds that the calculation of focal depth is heavily dependent on the largely unknown local propagation properties.

We gathered a learning set of 42 earthquakes documented by reliable instrumental data and by numerous intensity observations. Rather unexpectedly we observe (1) that within $50 \mathrm{~km}$ from the epicenter the ground motion attenuation rate is primarily controlled by focal depth and largely independent of magnitude; (2) that within this distance the fluctuations of crustal attenuation properties are negligible countrywide; and (3) that knowing both the depth and the expected epicentral intensity makes it possible to estimate a reliable magnitude.
\end{abstract}




\section{Introduction}

In addition to earthquake magnitude, the severity of seismic ground shaking at any given site is primarily controlled by its geometric spreading, by anelastic attenuation of the upper crustal rocks, and by hypocentral distance, i.e. the combination of horizontal distance and focal depth. Other parameters controlling the ground shaking include the earthquake radiation pattern, the rupture directivity, if any, and the inevitable site amplification effects.

When dealing with instrumental earthquakes, the magnitude, depth and focal mechanism - which in its turn determines the radiation pattern - are generally well known, and even the rupture directivity may be at least hypothesized if the recording network is dense enough. Things change drastically when dealing with historical earthquakes. For the vast majority of these events the severity of shaking is expressed by the macroseismic intensity reported at a number of sites, a rough proxy of a set of accelerometric records; for all the other parameters we can only make "informed inferences".

Nevertheless, given the limited length of the available instrumental record, historical earthquakes are the primary source of information for the assessment of seismic hazard, at any scale and with any approach. Historical catalogues are especially relevant for assessing seismic hazard in Italy; a country where average recurrence intervals for damaging earthquakes are very long compared with the length of the instrumental record, but where the historical record of the effects of strong ground shaking is extraordinarily long, spanning over a millennium. For all of these reasons, it is crucial to establish what information can be actually derived from intensity patterns and how reliable this information is.

Italy affords a unique opportunity to explore this often overlooked problem. In the early 1990's intensity data started being organized into analytical historical catalogues (see the Catalogue of Strong Italian Earthquakes, or CFTI: Boschi et al., 1995, 2000; Guidoboni et al., 2019), i.e. computer databases where all available individual intensity reports were stored in an orderly fashion, ready to be used for automatic and reproducible elaboration. Later on, the implementation of efficient, Internetbased data acquisition platforms has allowed the systematic investigation of intensity observations also at weak-motion levels, opening new avenues in the interpretation of earthquake propagation and site response. Starting in 2007, the platform Hai Sentito Il Terremoto (HSIT, Tosi et al., 2007; Sbarra et al., 2019b; De Rubeis et al., 2019) has been collecting over 1,290,000 felt reports supplied by ordinary people for Italian earthquakes of any size, mostly for weak motions.

Starting at the end of the 1990's, and following the inception of analytical historical catalogues, different workers developed computer algorithms for calculating the location, the magnitude, and even the presumed rupture orientation and length, for many well-documented pre-instrumental earthquakes (e.g., Musson, 1996; Bakun and Wentworth, 1997; Gasperini et al., 1999; Bakun et al., 2003; Bakun and Scotti, 2006).

Unlike instrumental data, which offer a variety of relevant independent observations (arrival times, amplitudes, phase delays), historical earthquake data are essentially mono-variable, meaning that all seismological parameters must be inferred from the same observation: the earthquake intensity. Nevertheless, the spatial variation of macroseismic intensity allows some of the source parameters to be derived. Within this line of research, Sbarra et al. (2019a) proposed a method for estimating the depth of pre-instrumental earthquakes of northern Italy, whereas other workers (e.g., Valensise et al., 2020) explored the possibility of inferring from intensity data also an indication of rupture directivity. 
Aside from the inevitable uncertainties that may arise from such a limited and often poorly distributed dataset, the monovariable nature of the data inevitably leads to the existence of trade-offs among magnitude and depth, because a deeper earthquake will generate smaller shaking, and may thus simply appear as a smaller event. In some cases the magnitude has been estimated without considering the depth, or by fixing it in advance. Other methods were based on a joint inversion of intensity data to obtain magnitude and depth (Traversa et al., 2018; Provost and Scotti, 2020). In any case, depth affects the observed macroesismic intensity and thus the apparent magnitude of each quake (Jánosi, 1906; Kövesligethy, 1907; Blake, 1941; Sponheuer, 1960; Ambraseys, 1985; Burton et al., 1985; Levret et al., 1996; Musson, 1996).

Gasperini et al. (1999) and Gasperini (2001) were certainly aware of these trade-offs (for example, see the discussion in Appendix 2 of Gasperini et al., 1999), but chose to take no countermeasure to minimize their impact. And since the learning set used for calibrating their method included almost exclusively instrumental earthquakes that ruptured within the shallowest portion of the crust, the magnitude values supplied by their method are accurate only for earthquakes occurring in that specific depth interval. Given the large variability of earthquake depth - in Italy as much as elsewhere - determining a reliable magnitude requires that earthquake depth is properly taken into account, especially in the case of lower crustal or subcrustal events.

At least in Italy, the limited consideration of the depth variability of damaging crustal earthquakes (in this work we are not concerned with subduction zone events) has often been explained with the inherent difficulty in evaluating the depth of historical earthquakes, motivated by an allegedly large variability in the propagation characteristics of the upper crust. Due to the known trade-off between earthquake depth and wave propagation properties, this viewpoint — and the resulting decision to fix the depth of historical earthquakes - led the natural variability of earthquake depth to be mapped in terms of variability of crustal properties. For all of these reasons, it is important to use a method capable of estimating depth and magnitude separately.

In this work we explore these issues, building on the findings of Sbarra et al. (2019a). More specifically:

- we first extend their experimental method to the whole Italian territory and to the whole pre-1984 earthquake catalogue (CPTI15 v 2.0, Rovida et al., 2019, 2020). This method was shown to be independent of magnitude, meaning that the slope of the attenuation curve calculated within $50 \mathrm{~km}$ from the epicenter is affected only by earthquake depth, not by earthquake size;

- then we develop a scheme for ranking objectively the quality of an intensity dataset, and hence for selecting only earthquakes that are suitable for the calculation of a reliable source depth;

- similarly to what was done by Sbarra et al. (2019a) for a northern Italy dataset, we derive intensity-depth equations from a learning set, i.e. a set of relatively recent Italian earthquakes for which both instrumental and macroseismic evidence is available, and use these equations to estimate the depth of the pre-instrumental events comprising our analyzed set. The approach adopted in the present work was specifically designed for analysing also larger magnitude earthquakes $\left(M_{w} \geq 6.75\right)$, because their causative fault cannot be assumed to be a point source and they are often characterized by sizable directivity effects; 
- finally, we derive from the learning set data a multiple regression equation relating expected epicentral intensity to magnitude and focal depth, in order to also estimate the magnitude of historical earthquakes from macroseismic data.

In the process we aim to 1) use our learning set to evaluate the role of crustal propagation properties (within $50 \mathrm{~km}$ of the epicenter) versus the variability of source depth, i.e. to explore the trade-off between these two parameters in different tectonic settings; and 2) discuss the potential implications of these developments for the estimation of seismic hazard. The inferred distribution of earthquake depth also has important seismotectonic implications, but these are beyond the scopes of this work and will be discussed in a further, dedicated paper.

\section{Seismotectonic complexity and depth variability of Italian earthquakes}

The Italian peninsula is located along the complex Africa-Europe convergent plate boundary. Due to this complexity, the causative sources of Italian earthquakes exhibit highly variable kinematics and geometrical parameters, as shown by focal mechanisms (Pondrelli et al., 2020) and active stress indicators (IPSI database, Mariucci and Montone, 2020), and as summarized by the DISS Database (Basili et al., 2008; DISS Working Group, 2021). More specifically:

- normal faulting dominates along the hinge of the Apennines chain and in the Calabrian Arc;

- thrust and reverse faulting is widespread along the external fronts of the Southern Alps and of the northern and central Apennines, in the northern and southern Tyrrhenian doman and in the Sicilian-Maghrebian Chain; and

- strike-slip faulting is found in northeastern Italy, in the most external portions of the central and southern Apennines and in the corresponding foreland areas (Figure. 1).

In addition, an active slab related to the subduction of the Ionian lithosphere exists below the Calabrian Arc: the slab is bounded by tear faults along its edges (Maesano et al., 2017, 2020).

The active faults and seismogenic sources identified so far in the Italian region belong both to extensional or compressional fault systems that formed during the presently active stress regime ("new faults"), or to structures that formed during previous tectonic phases and were later reactivated with different kinematics ("inherited faults"). While the new faults cut through the Alps and Apennines fold-and-thrust belts at relatively shallow depth, and are the expression of the ongoing compressional activity or extension due to back-arc stretching or ridge-top collapse, the inherited faults are generally rooted at deeper depth into the crust of the lower plate and are reactivated mostly with compressional and transcurrent faulting mechanisms. Their depth generally increases moving from the foreland areas, where they can be exposed at the surface (e.g. the Mattinata and Scicli-Ragusa fault systems in the Adriatic and Hyblean foreland areas; Di Bucci et al., 2010), towards the chain, following the increasing depth of the regional foreland monocline.

The inherited faults have been interpreted either as Mesozoic extensional structures characterizing the African northern passive margin and separating fossil paleogeographic domains (e.g., Scardia et al., 2015), or as long-lived faults of various origin, often perpendicular to the architecture of the more recent thrust belts (Zampieri et al., 2021). In addition to this general 


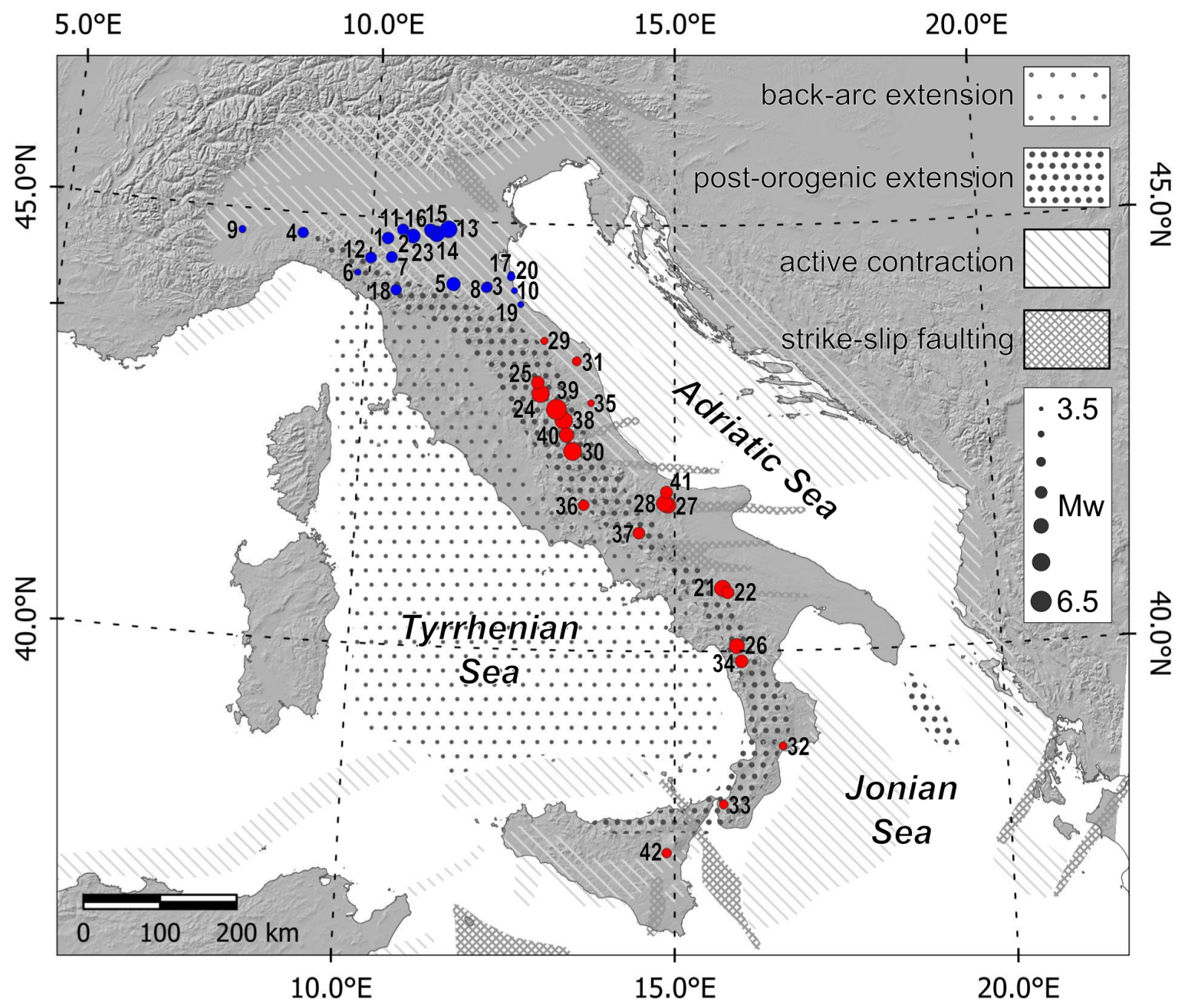

Figure 1. Location of the earthquakes used in this work and regional-scale tectonic information from the DISS database (DISS Working Group, 2021). The areas with different patterns indicate active tectonic domains that exist in the Italian peninsula and surrounding areas (from Vannoli et al., 2021). The learning set includes earthquakes that occurred in northern Italy, shown in blue (Table 1, IDs from 1 to 20 and 23), and in central and southern Italy, shown in red (Table 1, IDs from 21 to 42, except for 23).

rule, the recent 2016 Central Italy earthquake sequence has shown that also some large and older thrust faults occurring close to the extensional hinge of the chain may be negatively reactivated if favorably oriented with respect to the current stress field, thus becoming the causative sources of significant normal faulting earthquakes (Bonini et al., 2019; Buttinelli et al., 2021).

Finally, further evidence of the seismotectonic complexity of the Italian region is supplied by the control exerted by the inherited structural and paleogeographic grain of the African paleomargin, which resulted in the segmentation and differential retreat of independent panels of the "foreland monocline", i.e. of the subducting Adriatic, Ionian and Pelagian lithosphere 
(Mariotti and Doglioni, 2000; Scrocca et al., 2007). As a result of this process, major discontinuities perpendicular to the main structural trends of the Apennines fold-and-thrust belt developed at the boundaries of different foreland monocline panels (e.g., Rosenbaum and Piana Agostinetti, 2015; Vannoli et al., 2015). These discontinuities are highlighted by alignments of geofluid emissions and earthquake swarms (Vannoli et al., 2021), often characterized by transcurrent mechanisms and generally located at deeper depth with respect to the new faults, either extensional or compressional.

As a result of this framework, Italian earthquakes exhibit an unusually broad depth range, mainly as a function of their faulting mechanism and of their location in the upper or lower plate (e.g., Chiarabba and De Gori, 2016). They can be grouped in at least four independent depth classes:

- very shallow in the active volcanic areas of the Perityrrhenian margin and of Sicily $(\leq 5 \mathrm{~km})$;

- shallow ( $<15 \mathrm{~km}$ depth) in both the internal and external domains of the orogen;

- shallow-intermediate $(15-30 \mathrm{~km})$ in the foreland areas and along large lithospheric tears cutting through the Adriatic monocline and the Apennines (Vannoli et al., 2015);

- deep (up to $600 \mathrm{~km}$ depth) in the subduction system below the Calabrian Arc (Chiarabba et al., 2008).

The earthquakes generated by the new faults and by the inherited faults are often geographically overlapped, as seen in the Po Plain (Sbarra et al., 2019a), making it difficult to understand which is which from the epicentral location alone. Assigning each pre-instrumental earthquake to a specific depth class helps assigning that event to its relevant domain, thus greatly supporting its seismotectonic interpretation and the calculation of accurate global earthquake budgets and rates.

\section{Method and results}

We updated and extended the method proposed in Sbarra et al. (2019a) to make it suitable for use on earthquakes of the entire Italian peninsula through an automated procedure.

As in Sbarra et al. (2019a), we adopt a distance binning method. Using only well-located instrumental earthquakes we first calculate the intensity average of individual Macroseismic Data Points (MDPs) falling within $10 \mathrm{~km}$-wide ring-shaped moving windows, so as to obtain an intensity attenuation curve. In most cases the trend of this curve shows an abrupt drop in the attenuation beyond an epicentral distance of about $50 \mathrm{~km}$, as described in Fah and Panza (1994) and Gasperini (2001) and verified experimentally by Sbarra et al. (2019a). For this reason, we calculate the slope of the line that best fits only the first 50 $\mathrm{km}$ of the attenuation curve.

In the following step we plot the instrumental depth of the earthquakes used as a learning set versus the slope of the attenuation curve. By fitting these values we obtain a logarithmic function that is then used for the last step, that is, to infer the depth of the non-instrumental earthquakes of our analyzed set.

Notice that the size of our circular moving windows is now calculated from the earthquake epicenter rather than from the innermost MDP average, as proposed by Sbarra et al. (2019a). This minor improvement makes the algorithm more uniform 
across the full earthquake magnitude range. The new procedure is summarized in Figure 2 with reference to a specific recent earthquake (20 May 2012; ID 13 of Table 1). After drawing the first $10 \mathrm{~km}$-wide, circular search area centered in the epicenter, and the following nine $10 \mathrm{~km}$-wide ring-shaped search areas, each one shifted by $5 \mathrm{~km}$ from the previous one $(0-10,5-15$, 10-20, 15-25, 20-30, 25-35, 30-40, 35-45, 40-50 and 45-55 km: red and blue lines in Figure 2b, up to the distance of 55 $\mathrm{km}$ from the epicenter, the resulting 10 intensity estimates of averaged MDPs are used to build the attenuation diagram (Figure 2c).
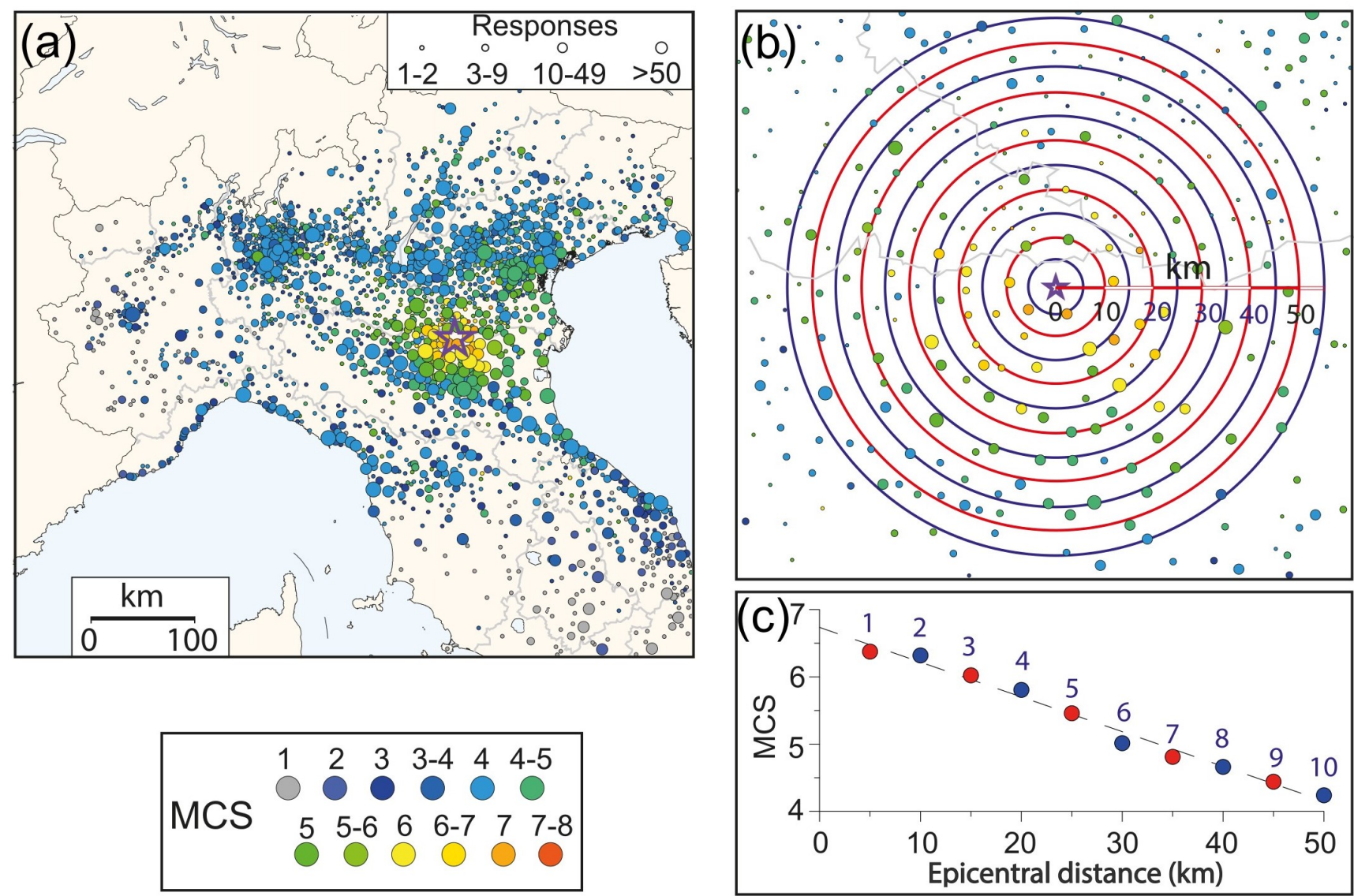

Figure 2. Workflow of the moving windows procedure. a) Macroseismic field of the 20 May 2012 earthquake (ID 13 in Table 1) from the HSIT database (available from: https://e.hsit.it/772691/index.html); b) map showing the first $50 \mathrm{~km}$ from the epicenter and the ten ringshaped search areas centered in the epicenter (shown by red and blue lines), each one shifted by $5 \mathrm{~km}$ with respect to the previous one; c) plot of the 10 intensity values obtained averaging the MDPs falling in each of the rings: \#1 reports the average intensity calculated for the 0-10 km search area, \#2 the average intensity for the 5-15 km search area, and so on. 


\subsection{Data selection criteria}

To compose our learning set (Table 1) we searched the whole Italian territory, selecting all instrumentally well documented earthquakes that also feature good quality macroseismic information. As in Sbarra et al. (2019a) we built a learning-set comprising macroseismic data obtained either from a direct survey or collected through the web, so as to gather information to be used as a sort of "Rosetta stone" for obtaining the parameters of historical earthquakes. For pre-2007 events we used the data stored in the DBMI15 v2.0 catalogue (Locati et al., 2019), a compilation of macroseismic intensities for Italian earthquakes that occurred in the time window $1000 \mathrm{CE}-2017$, whereas for more recent events of $M_{w} \leq 5.9$ we either used intensity data from the web-based HSIT catalogue (Tosi et al., 2007; De Rubeis et al., 2019; Sbarra et al., 2019b), or used the MDPs collected by targeted post-earthquake surveys conducted by experienced INGV-QUEST personnel (QUick Earthquake Survey Team; http://www.ingv.it/quest/index.php/rilievi-macrosismici; last accessed on 20 December 2021). Only for the $M_{w} 5.5,18$ January 2017 event we had to make an exception to this rule, due to the incompleteness of HSIT data caused by the evacuations following the $M_{w} 6.0$ mainshock of 24 August 2016.

The events comprising the learning set were further selected based on the following criteria:

1. pre-2007 earthquakes must have $M_{w} \geq 5.0$, but events of $M_{w} \geq 4.5$ are also accepted if there exists an associated targeted study;

2. post-2007 earthquakes must have $M_{w} \geq 4.0$ if their depth is $>25 \mathrm{~km}$, or $M_{w} \geq 4.5$ if their depth is $\leq 25 \mathrm{~km}$;

3. the earthquake depth must not have been fixed a priori by INGV's National Seismic Network;

4. only for pre-2012 earthquakes, the event must not be an aftershock occurring within a week of the mainshock, or a foreshock that occurred less than 24 hours before the mainshock;

5. all earthquakes having $M_{w} \leq 5.8$ must not be aftershocks of the central Italy sequence of 2016;

6. the earthquake must be documented by at least 100 MDPs (as in Sbarra et al., 2019a), at least 60 of which must fall within the first $55 \mathrm{~km}$ from the epicenter;

7. the MDPs falling at a $10-55 \mathrm{~km}$ distance from the epicenter must be distributed in an azimuth range $>180^{\circ}$;

8. the attenuation slope must be calculated based on six or more averaged points;

9. the standard error of the estimated attenuation slope must be $\leq 0.01$.

All 42 earthquakes listed in Table 1 fulfill these rather strict criteria with the only exception of \#6 and \#17 (MDP < 60), two deeper events that were already included in the learning set of Sbarra et al. (2019a) as they are crucial for characterizing lower crustal and subcrustal seismicity.

Notice that the selection criteria 1-4 had already been adopted by Sbarra et al. (2019a). The additional criteria (5 through 9) were added in consideration that the present work deals with the entire Italian territory, and hence with a much larger diversity of the potentially concerned earthquakes. More specifically: 
- criterion \#5 was added due to the recurring lack of data in the epicentral areas of the main aftershocks of the 2016-2017, central Italy sequence, due to the widespread evacuations following the $M_{w} 6.0$ mainshock of 24 August 2016 and to the superposition of the effects of subsequent shocks;

- criterion \#6 was added after various experimental tests, in order to achieve more reliable and stable estimates of the attenuation;

- criteria \#7 and \#8 were introduced to discard earthquakes located offshore or near the coastline, whose epicentral location generally exhibits greater uncertainty;

- criterion \#9 was adopted to retain only earthquakes for which we could calculate a reliable attenuation slope.

\subsection{Analysis of the learning set}

We analyzed separately two data subsets, respectively comprising only earthquakes located in Northern Italy, and earthquakes located in the rest of the Italian peninsula. We made this choice because the dataset used in Sbarra et al. (2019a) included only earthquakes from a region whose lithospheric structure and wave propagation properties are rather homogeneous; conversely, in this work we wanted to evaluate the possible influence of variable attenuation properties resulting from the full range of tectonic and geodynamic diversity characterizing the Italian peninsula.

Due to the intervening minor updates in our methodology — and specifically in the calculation of the starting point of our moving window, which implies a slightly different slope for the first $50 \mathrm{~km}$ of the attenuation curve - we first recalculated the attenuation slope for all the 20 earthquakes comprising the learning set used by Sbarra et al. (2019a) (Table 1, ID from 1 to 20; see Figures 1 and 3). We added to this dataset the 1996, Emilia earthquake (ID 23), originally rejected because its depth from the ISIDe catalogue (ISIDe Working Group, 2007) was fixed at $10 \mathrm{~km}$; for this event we now use the depth evaluated by Selvaggi et al. (2001). We then analyzed the earthquakes we selected for the rest of Italy and calculated their intensity attenuation slope (Figures 1, 4; Table 1, from \#21 to \#42, except for \#23).

As discussed earlier, in both datasets, which together form our new learning set, we observed a distinct break in slope at an epicentral distance of about $50 \mathrm{~km}$. In describing this feature of the Italian attenuation curves, Gasperini (2001) contended that within a $\sim 50 \mathrm{~km}$ epicentral distance the ground shaking is dominated by direct seismic phases, whose propagation is highly sensitive to earthquake depth, whereas Moho-reflected phases dominate at larger distances. According to this hypothesis, the exact distance of the transition would be controlled by the average Moho depth along the source-receiver path.

For all the earthquakes of the learning set we then plotted the steepness (S), i.e. the absolute value of the slope, versus focal depth (D), and found two separate but very similar best-fitting logarithmic functions (Figure 5). For northern Italy we found

$S=(-0.020 \pm 0.003) \ln D+0.093 \pm 0.009$

whereas for central and southern Italy we found 

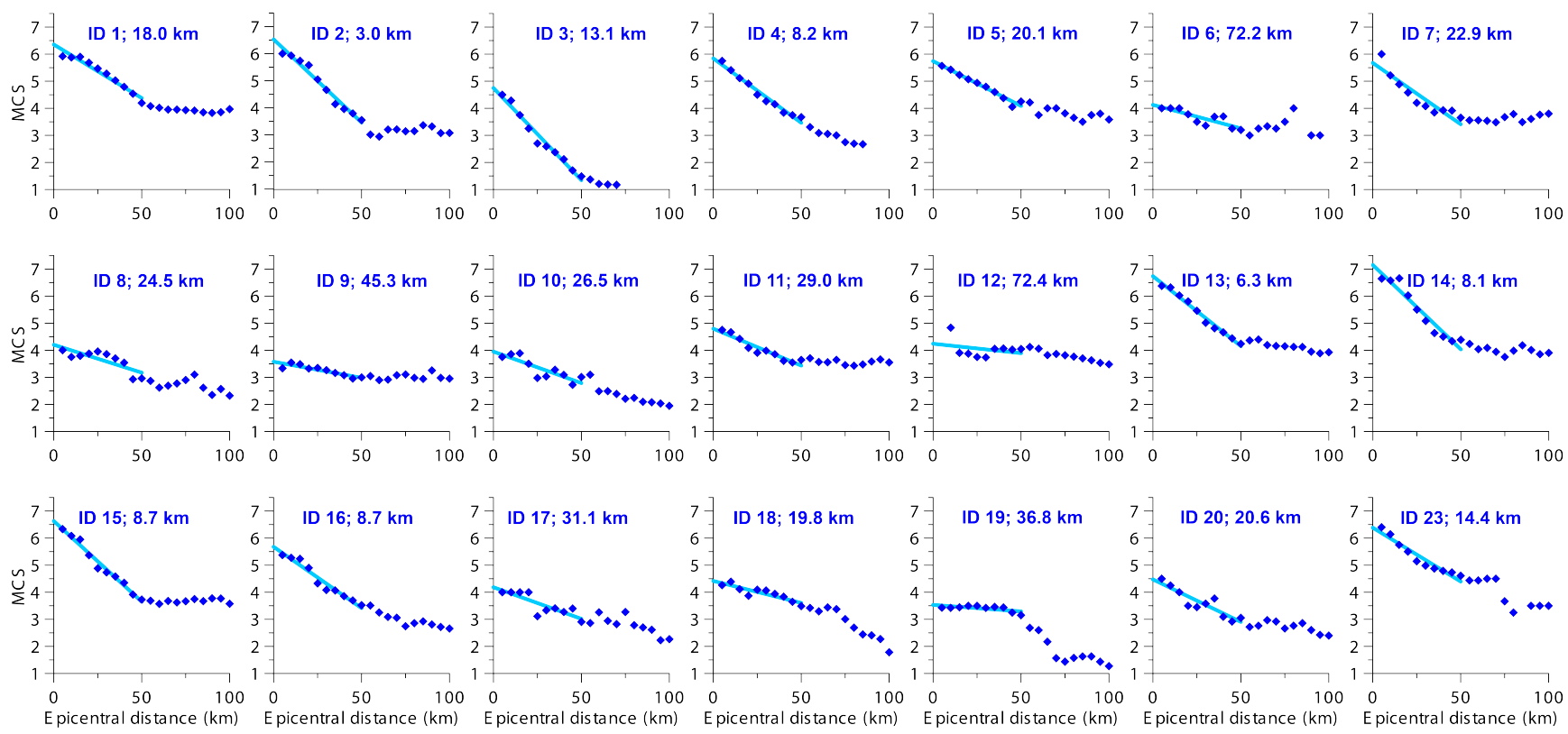

Figure 3. Attenuation curves obtained for the northern Italy earthquakes of the learning set (Table 1, from \#1 to \#20, plus \#23; blue symbols in Figures 1, 5. Individual intensity data points were obtained by averaging the intensity values as shown in Figure 2. We obtained the linear fit for the first $50 \mathrm{~km}$ of each curve and calculated the resulting slope.

$S=(-0.016 \pm 0.003) \ln D+0.079 \pm 0.009$

The coefficients of both these functions fall within their combined confidence limits, suggesting that our method does not detect any statistically significant change in the attenuation properties between the two domains, at least over the first $50 \mathrm{~km}$ of epicentral distance. This finding also suggests that an approach based on averaging the intensity values distributed over circular search areas has the ability to smooth out most of the inevitable azimuthal differences in crustal propagation properties.

We decided to calculate a new logarithmic function using all 42 earthquakes of the learning set, so as to obtain a law that may be used over the whole Italian region (green line in Figure 5):

$S=(-0.018 \pm 0.002) \ln D+0.087 \pm 0.006$

The Pearson coefficients of the three regressions are quite good, corresponding to a significance level of correlation better than $10^{-3}$. As we expected, Eq. 3 is similar to the previous two equations, and exhibits a narrower $95 \%$ confidence interval resulting from the larger number of available data points. Eq. 3 can be applied for a steepness interval $0.058 \leq S \leq 0.012$, which corresponds to a depth interval $5 \leq D \leq 73 \mathrm{~km}$. Notice that the function is not constrained beyond these limits, and hence should not be used for shallower or deeper events. Notice also that for epicentral distances $>50 \mathrm{~km}$ the curves shown in Figures 

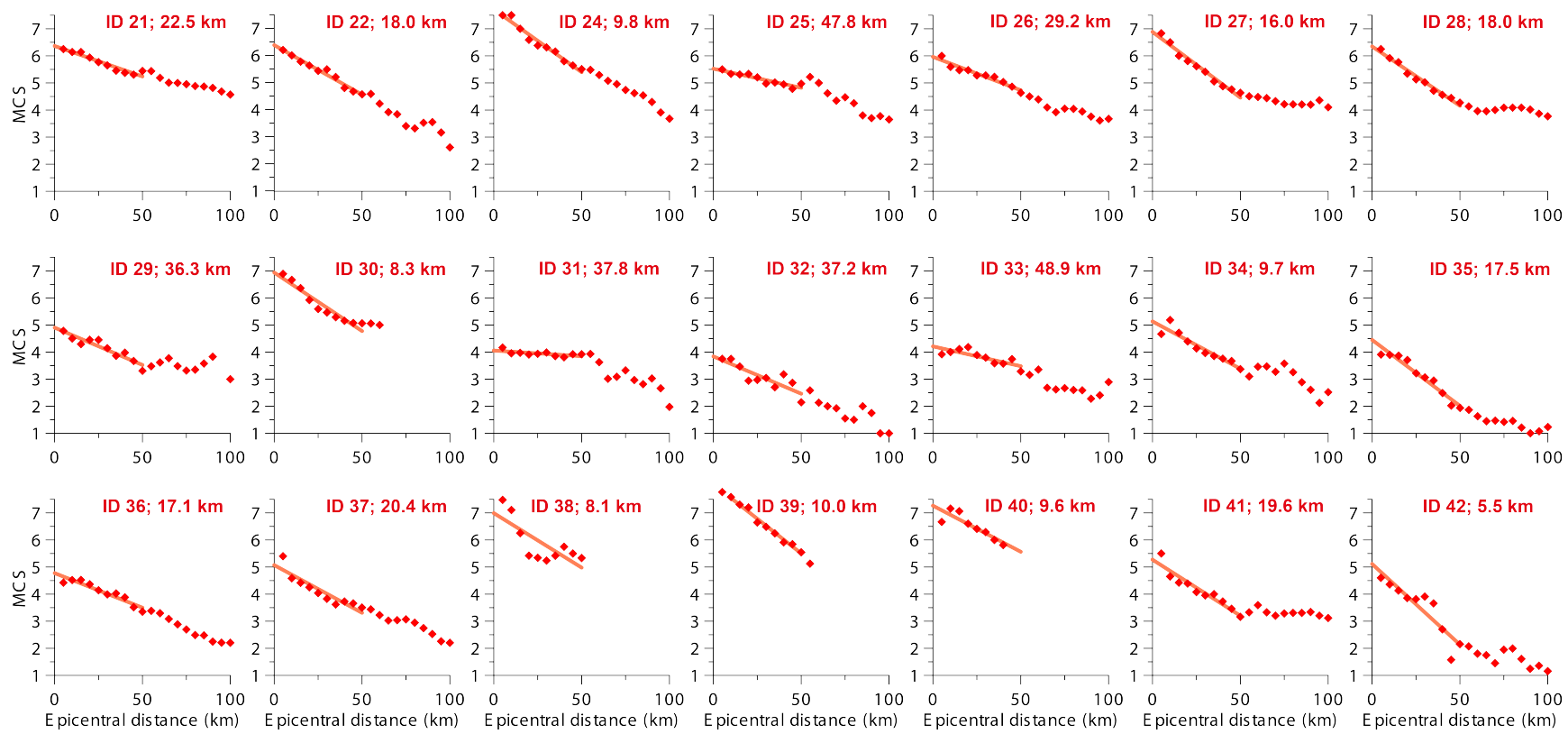

Figure 4. Attenuation curves obtained for the central and southern Italy earthquakes of the learning set (Table 1, from \#21 to \#42, except for \#23; red symbols in Figures 1 and 5). Individual intensity data points were obtained by averaging the intensity values as shown in Figure 2. We obtained the linear fit for the first $50 \mathrm{~km}$ of each curve and calculated the resulting slope.

3 and 4 exhibit different attenuation between the northern and the central-southern Italy datasets, but are remarkably similar in the first $50 \mathrm{~km}$, in agreement with the observations made by Gasperini (2001). In particular, the attenuation of earthquakes occurring in northern Italy, where the crust is generally thicker than in the rest of the country, shows a characteristic, very gently sloping plateau that has been interpreted as due to Moho reflected seismic waves by Bragato et al. (2011).

A further element to be taken into account is the difference in seismic wave propagation between the Tyrrhenian and Adriatic sides of Italy, most likely resulting from a rather different efficiency of the crust-upper mantle system (Mele et al., 1997; Lolli et al., 2015; De Rubeis et al., 2016; Di Bona, 2016). This difference, however, can only be appreciated in the far-field, i.e. beyond a $50 \mathrm{~km}$ distance from the epicenter, implying that most likely it does not show in our analyses, nor does it affect their results.

Finally, using the new learning set we obtained a new Intensity Prediction Equation (IPE) for Italy (4):

$I=(-3.08 \pm 0.02) \log r+(0.94 \pm 0.01) M_{w}+4.47 \pm 0.07$

where $I$ is the intensity and $\mathrm{r}$ is the hypocentral distance in $\mathrm{km}$. This equation rests on the assumption that the macroseismic fields used to build it contain fairly well-distributed data, both in the near-field and in the far-field. 


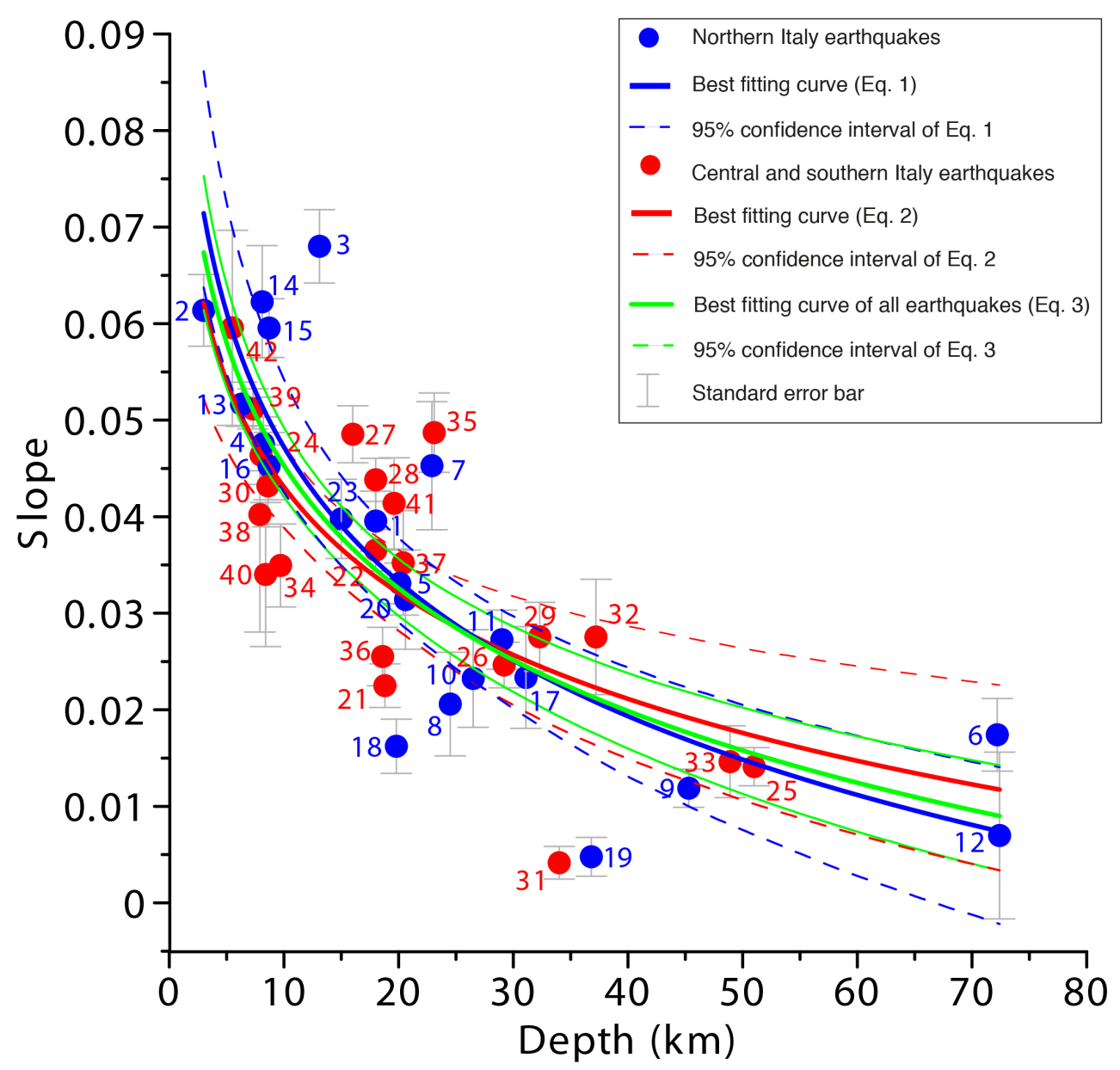

Figure 5. Depth versus attenuation slope for the 42 earthquakes used as a learning set. Blue and red symbols indicate the northern Italy and the central and southern Italy datasets, respectively: the corresponding best fitting logarithmic functions are shown in blue (Eq. 1) and red (Eq. 2), respectively, along with their 95\% confidence intervals. The best fitting function obtained for the whole dataset (Eq. 3) is shown in green. Each earthquake is labelled with a unique identifier (see Table 1) and is plotted along with its standard error (shown by a vertical bar).

\subsection{Independence of earthquake depth from magnitude}

The slope of the first $50 \mathrm{~km}$ of the attenuation curves calculated for the earthquakes of our learning set (Figures 3,4 ) is independent from magnitude, as already experimentally observed by Sbarra et al. (2019a) for a smaller sample of events. To prove this statement we plotted in Figure 6a the attenuation curves for four earthquakes falling in the $M_{w}$ range 4.8-6.5, but having a similar instrumental depth, in the range 7.3-8.7 km (\#4, 16, 24, 39; see Table 1). Figure 6a shows that all the calculated steepness values fall in a rather narrow range (0.045-0.051), regardless of magnitude. Figure $6 \mathrm{~b}$ shows that the same behavior 
is observed also for four deeper earthquakes (\#8, 10, 11, 26; see Table 1, which share a similar instrumental depth (24.5-29.2 $\mathrm{km})$ but exhibit a different $M_{w}$ (4.0-5.6).
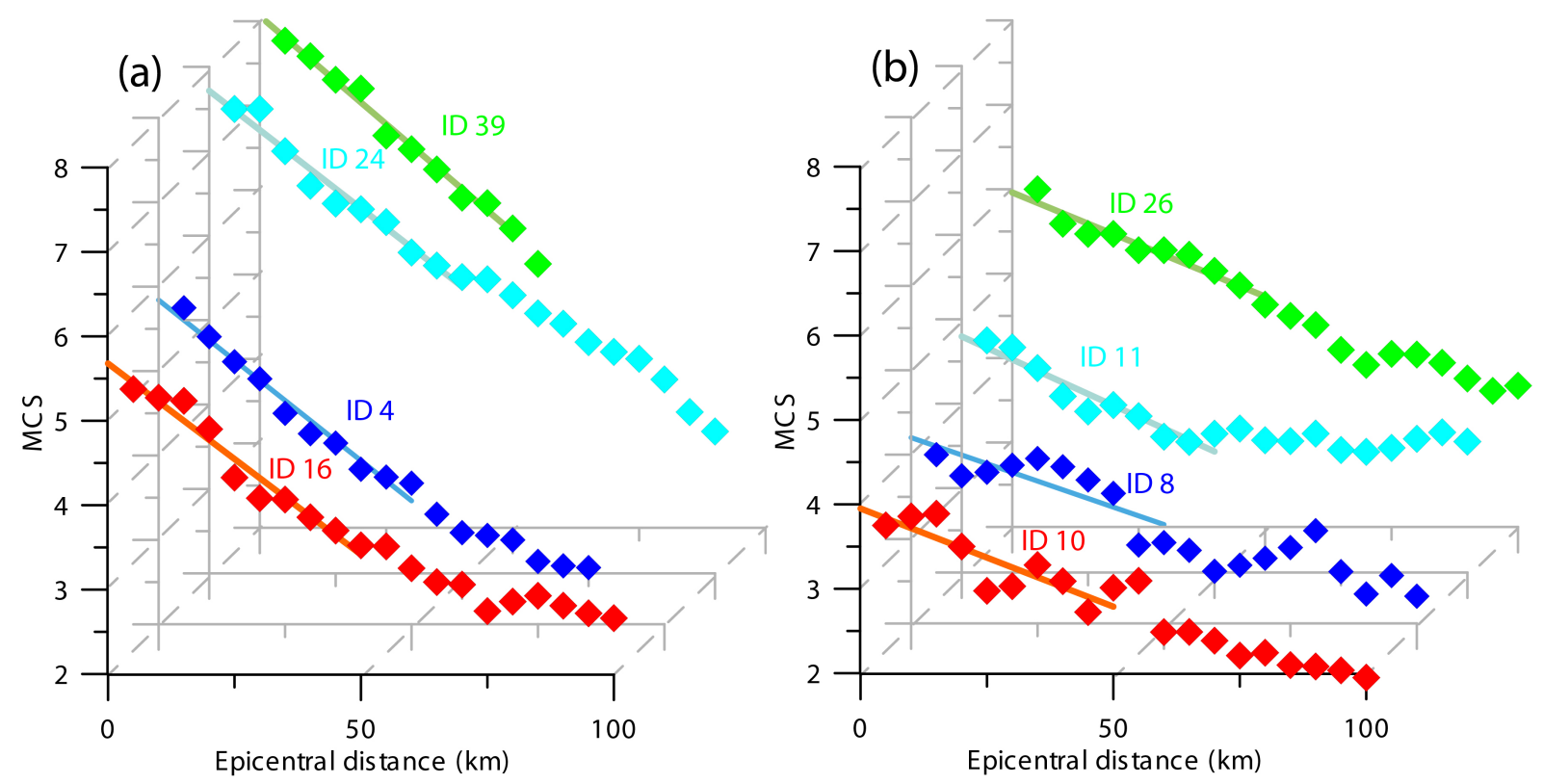

Figure 6. Attenuation curves obtained for two groups of earthquakes featuring a similar hypocentral depth but a different magnitude: (a) for the shallow events \#4, 16, 24, and 39; (b) and for the deep events \#8, 10, 11 and 26 (see Table 1 for further details). The slope of the bestfitting line in the first $50 \mathrm{~km}$ is similar among the four events reported for each group, providing experimental evidence for the independence of depth from magnitude.

The invariance of the attenuation slope with magnitude is a key point as it makes our approach suitable for analyzing historical earthquakes even if their size is not well constrained. On the contrary, nearly all the methodologies developed in the past to calculate earthquake depth use magnitude as an essential input parameter (Jánosi, 1906; Kövesligethy, 1907; Blake, 1941; Sponheuer, 1960; Ambraseys, 1985; Burton et al., 1985; Levret et al., 1996; Musson, 1996; Traversa et al., 2018; Provost and Scotti, 2020).

\subsection{A logarithmic law to determine earthquake depth}

We analyzed the possibility of reproducing the experimental trend of Figure 5 through predictive models, expressing the macroseismic intensity (Intensity Prediction Equations, IPE) or the Peak Ground Acceleration (PGA) as a function of the earthquake magnitude and distance. It is worth noting that many of the IPEs and GMPEs (Ground Motion Prediction Equations) proposed in the literature (e.g., Douglas, 2003, 2021) assume a predetermined depth for all earthquakes considered. The endemic lack of interest for this parameter is likely due to the uncertainty associated with the depth itself, not only for historical earthquakes but also for recent events located in areas that are geologically complex, or not monitored by a dense seismic network, or 
both. To explore the variation of the attenuation slope with depth we therefore used three of the models that explicitly include this parameter: our new IPE (Eq. 4), the IPE by Musson (2005), and the GMPE by Cauzzi and Faccioli (2008). We chose these functions because they feature a simple functional form which determines a magnitude-independent attenuation slope, as suggested by real earthquake data. Conversely, a functional form containing a magnitude-distance mixed term would lead to a change in the shape of the attenuation curve with distance and to a variation of the slope for a variable magnitude.

We then used two different conversion equations (Faenza and Michelini, 2010; Masi et al., 2020) to turn the PGA values obtained with the adopted GMPEs into macroseismic intensities, so as to also test the influence of the conversion process. We used these equations to compute the macroseismic intensities caused at several epicentral distances by a hypothetical earthquake located at variable depth. We then applied the same $10 \mathrm{~km}$-moving window average method used for the analyzed earthquakes and calculated the regression line within a distance of $50 \mathrm{~km}$.

Figure 7a shows some of the average intensity values obtained using the IPE proposed by Musson (2005), along with their regression lines. We remark that, although the macroseismic intensity is proportional to the logarithm of the hypocentral distance, the linear regression of intensity versus epicentral distance gives statistically significant results in the adopted distance range. Figure $7 \mathrm{~b}$ shows the steepness of the regression lines thus calculated as a function of the earthquake focal depth, and the values, calculated with the same method, derived from PGA (using the GMPE proposed by Cauzzi and Faccioli (2008), converted into macroseismic intensity. It is worth noting that the differences caused by the use of the IPE in place of the GMPE are comparable to the differences caused by the use of two different conversion equations. At any rate, in all three cases the trend of the values as a function of the depth is similar to that found experimentally. Also for these synthetic data, the Pearson coefficients of the four linear regressions between the steepness and the logarithm of focal depth $(R=0.995)$ are significant, with a probability of less than $10^{-3}$ to find by chance the same regression in uncorrelated data. Having been obtained with a completely different kind of data, this result suggests that the approach followed for deriving Eq. 3 is adequate and reliable.

\subsection{Reliability and validation of the depth estimation method}

The reliability of the slope of the first $50 \mathrm{~km}$ of the attenuation curve depends on the quality and spatial distribution of the available MDPs and on the accuracy of the epicentral locations. Italian macroseismic data are systematically stored in the DBMI database v2.0 (Locati et al., 2019); as a rule of thumb, the older is the earthquake, the less complete and reliable are the historical sources from which macroseismic intensities were derived (e.g., Guidoboni and Ebel, 2009).

To test our procedure we investigated the minimum number of MDPs of the macroseismic field that are needed to obtain a reliable estimate of the attenuation slope. To this end we intentionally depleted the macroseismic field of the 20 May $2012, M_{w}$ 5.8, Emilia earthquake (\#13), a well-recorded event for which over two hundred spatially well-distributed MDPs are available, using data from the HSIT database (De Rubeis et al., 2019); Figure 2a. For each of the ten ring-shaped search areas (see Figure $2 \mathrm{~b}, 2 \mathrm{c}$ ) we performed a gradually increasing reduction of the number of MDPs (from $1 \%$ to $99 \%$ ), the same for each step and for all areas. The regression of the attenuation trend was calculated 1,000 times for each depletion step, so as to evaluate the steepness variability through its standard deviation. 

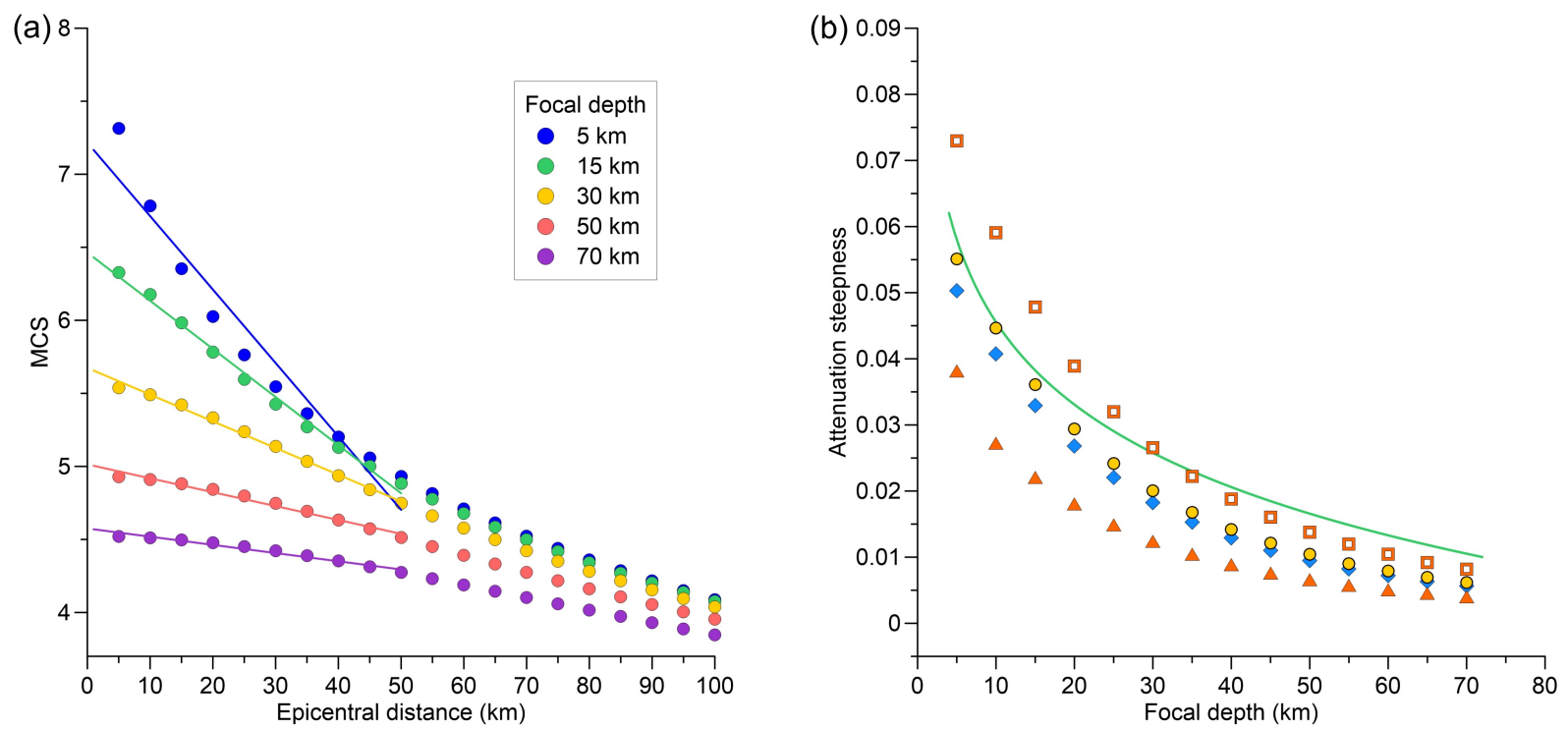

Figure 7. Attenuation curves and slopes simulated with different intensity models for a M 5.0 earthquake located at different depths. a) averaged intensity calculated using the IPE by Musson (2005) and the corresponding regression lines. b) attenuation steepness of intensities simulated using the IPE by Musson (2005) (blue diamonds), the IPE of Eq. 4 (yellow dots), and the GMPE by Cauzzi and Faccioli (2008); the PGAs predicted by this latter equation have been converted into MCS using the equations provided by Faenza and Michelini (2010) (orange squares) and by Masi et al. (2020) (orange triangles), respectively. All predictions are compared with the experimental Eq. 6, shown by the green line in panel b).

Figure 8 shows the number of MDPs versus the standard deviation of the steepness, which is equal to 0.01 when only $14 \%$ of the total data are left, corresponding to 30 MDPs; this implies that the most likely steepness values (68\%) fall within a standard deviation equal to \pm 0.01 . As a consequence, we decided to use 30 MDPs as a minimum threshold for the analyzed set, instead of the 60 MDPs minimum used for the learning set. For deriving Eq. 3 we use an even more conservative selection of learning set data, in consideration that ultimately this is the equation used to infer the depth of historical earthquakes countrywide.

Our depletion test demonstrates that we may obtain a reliable attenuation slope — and hence a reliable depth estimation even for historical earthquakes for which only few MDPs are available, provided that they are homogeneously distributed for each distance window.

We remark that the reliability of our estimates improves significantly when the value of each of the variables indicated by our selection criteria \#6 to \#9 (number of MDPs within $55 \mathrm{~km}$, azimuthal range, number of used circular windows, and standard error: see Sect. 3.1) rises above the average value calculated for all 206 selected events. Therefore, the steepness values obtained through our methodology are more reliable if the macroseismic field includes more than 99 MDPs within the first $55 \mathrm{~km}$ from the epicenter, distributed over an azimuthal range $>270^{\circ}$, its attenuation curve is described by 10 averaged points and the standard error is $<0.0058$, implying that the data points are well aligned on a straight line (see Table S1). 


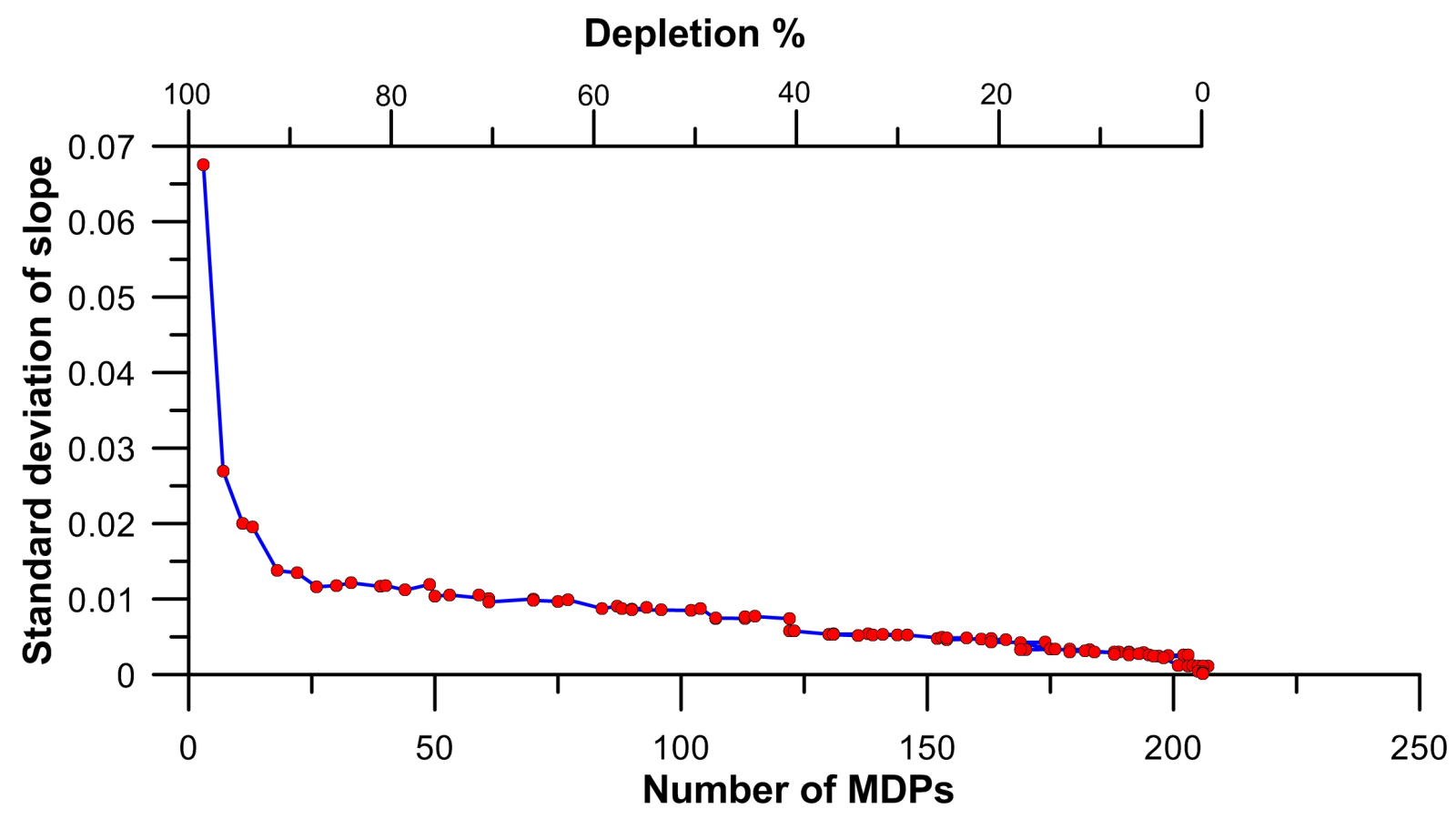

Figure 8. Application of the depletion test to the macroseismic field of the 20 May 2012 earthquake (Figures 1, 2; ID 13 in Table 1) taken from the HSIT database (available from: https://e.hsit.it/772691/index.html), for which there exist 207 MDPs falling within a radius of 55 $\mathrm{km}$ from the epicenter. The $\%$ of MDPs falling within each ring-shaped area (see Figure 1) was gradually depleted from $1 \%$ to $99 \%$, and the slope was calculated 1,000 times for all the different depleted datasets. The Y-axis shows the variability of the calculated slope, expressed through the standard deviation of the slope obtained for the depleted datasets with the same number of MDPs.

A problem that could lead to inaccurate depth estimates is the cumulative damage caused by earthquakes that occurred close in time and space. For instance, we analyzed the 29 May 2012, $M_{w}$ 5.7, Emilia earthquake, one of the learning set events, using the MDPs from DBMI15 instead of those supplied by HSIT. For this event the DBMI macroseismic field (Tertulliani et al., 2012, ttps://emidius.mi.ingv.it/ASMI/event/20120529_0700_000) includes the effects of the 20 May event $\left(M_{w} 5.9\right.$; https://emidius.mi.ingv.it/ASMI/event/20120520_0203_000), which occurred nearby. These circumstances misled our method, causing a drastic overestimation of the earthquake depth $(36.8 \mathrm{~km})$. Conversely, thanks to the rapidity in the response given by citizens and to the ensuing lack of contamination, the HSIT dataset method returned a depth $\leq 5 \mathrm{~km}$, much closer to instrumental estimate $(8.1 \mathrm{~km})$.

\subsection{A two-step method for estimating magnitude based on intensity and depth}

While the focal depth is independent of magnitude and can be obtained simply based on the steepness of the line that best fits the first $50 \mathrm{~km}$ of the attenuation curve, the estimation of the magnitude itself affects the $y$-intercept (the expected intensity at the epicenter, $I_{E}$ ) of the linear fit (Figure 6): for a constant depth the $y$-intercept increases for an increasing magnitude 
(Figure 6), and decreases if depth increases. Therefore, a reliable magnitude determination based on macroseismic data must necessarily take into account earthquake depth.

The method used in this work to estimate magnitude differs from that described by Sbarra et al. (2019a), where magnitude was calculated simply by reversing the IPE proposed by Tosi et al. (2015). To determine magnitude more reliably we devised a two-step procedure where depth is estimated first (Step 1), then $M_{w}$ is estimated using our learning set data to derive a standard least squares regression equation among D (depth), $I_{E}$ and $M_{w}$ (Step 2). Figure 9 shows the learning set data and the contour lines of the function that accounts for the geometrical spreading from the hypocenter to the epicenter:

$M_{w}=(0.18 \pm 0.09) \ln D+(0.56 \pm 0.06) I_{E}+(1.44 \pm 0.53)$

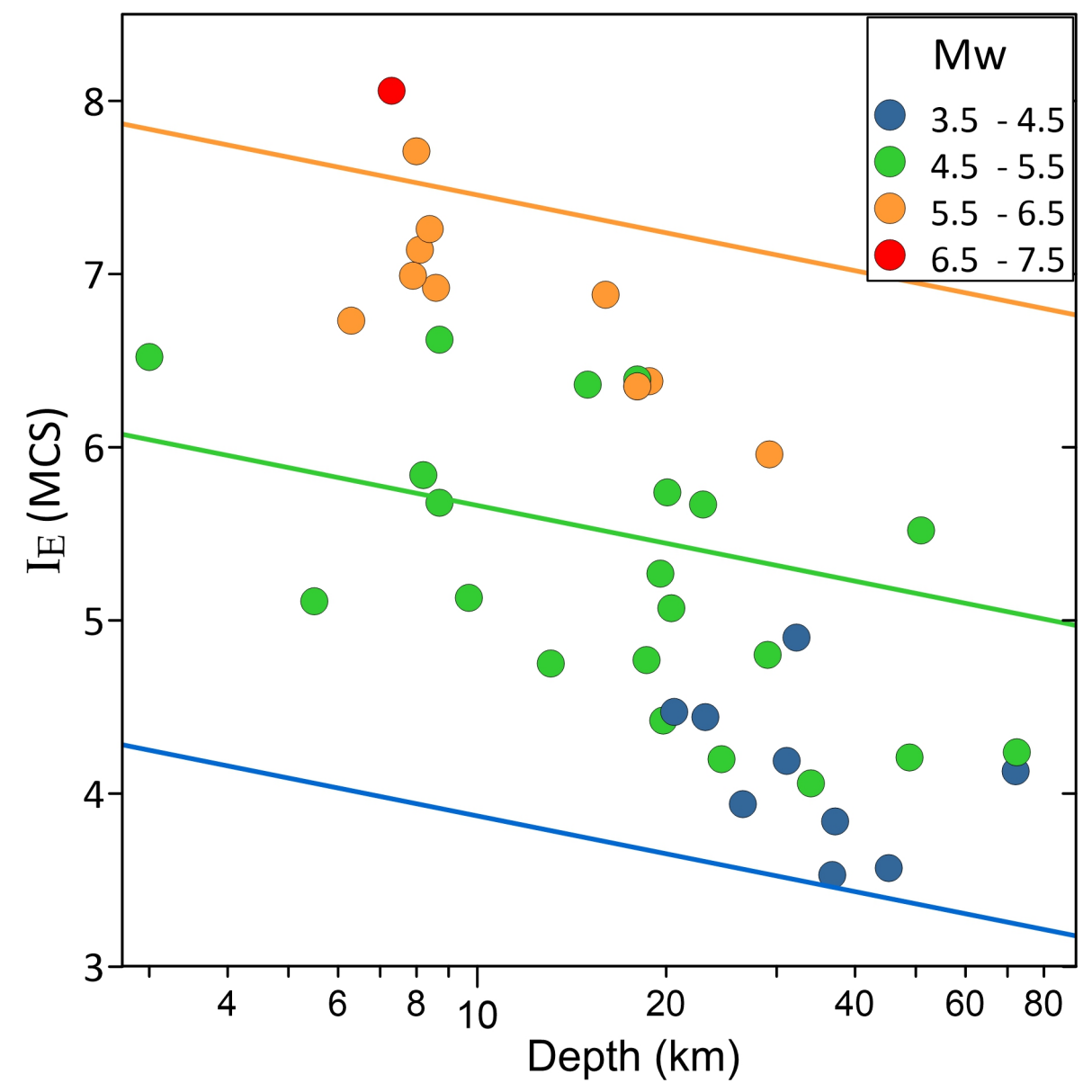

Figure 9. Magnitude as a function of the natural logarithm of depth, and expected intensities for all earthquakes of the learning set (colored dots). The multiple regression function (Eq. 5) is shown with colored lines. 
Magnitudes obtained through this procedure are referred to as y-intercept $M_{w}$. In this perspective the attenuation curve becomes a sort of 'earthquake identity card', as it contains all the elements needed to retrieve magnitude and depth from the observed intensities, provided that a reliable calibration scheme is available. Such calibration can be regarded as an application to Seismology of the principle of actualism popularized by British naturalists in the late 18th century: "Observing modern earthquakes to understand those of the past".

The method summarized by Eqs. 3 and 5 is simpler and more intuitive than the methods based on a joint inversion of magnitude and depth (Musson, 1996; Bakun and Wentworth, 1997; Sirovich et al., 2013; Traversa et al., 2018; Provost and Scotti, 2020), plus it may allow a geological verification of the depth before estimating the magnitude. Our Step 2 uses a method similar to that proposed by Gutdeutsch et al. (2002), who applied it to carefully selected datasets only, so as to minimize the bias caused by a poorly constrained depth or by an incomplete macroseismic field.

In conclusion, starting from our experimental observations of the independence of the attenuation slope from magnitude, we were able to mitigate the trade-off between magnitude and depth when estimating both these parameters from macroseismic data.

\subsection{Dealing with larger magnitude earthquakes}

Our approach works well if the size of the seismic source is negligible relative to the epicentral distances, but it may not be immediately applicable to estimate the attenuation of the macroseismic intensity for a large magnitude earthquake (Gasperini, 2001; Albarello and D'Amico, 2004; Pasolini et al., 2008). To test the validity and possible limitations of this assumption we evaluated the maximum magnitude for which the use of a point-source approximation is granted, using both our learning set and our analyzed set.

We used the empirical relationships proposed by Wells and Coppersmith (1994) to calculate the rupture area and the expected length of the seismogenic source based on the $y$-intercept $M_{w}$ (Eq. 5). Assuming a dip angle of $45^{\circ}$ for every fault, irrespective of its kinematics and tectonic setting, we calculated the surface projection of each rectangular source and the radius $R_{e}$ of the equivalent circle (i.e. a circle having the same projected area as the fault: thus $R_{e}$ is a function of $M_{w}$ ). We found $R_{e}$ greater than $10 \mathrm{~km}$ only for earthquakes of $M_{w} \geq 6.75$; but not having any such earthquakes in the learning set (Table 1), we used a geometric correction only to infer the depth of 21 earthquakes of the analyzed set (see discussion at the end of this section and in Table S1).

Then we applied to this group of larger magnitude earthquakes a procedure that we call "variable moving windows". More specifically, we used as the first search area a circular window of radius $R_{e}$, inside which we averaged the MDPs intensities, while for the subsequent windows - each one shifted by $5 \mathrm{~km}$, as usual - we adopted the standard $10 \mathrm{~km}$ radius increase. For the 13 January 1915, $M_{w}$ 7.1, Marsica (central Apennines) earthquake, one of the largest in Italian history, we made a test using the $R_{J B}$ distance (Joyner and Boore, 1981) and calculating the average of the MDPs inside a rectangular rather than a ring-shaped area. We singled out this earthquake because its macroseismic field should not have been contaminated by the effects of previous significant events, which make it difficult to separate the individual contribution of a specific shock to the cumulative damage (Grünthal, 1998; Grimaz and Malisan, 2017; Graziani et al., 2019); a circumstance that would ultimately 
affect the attenuation slope and hence contaminate the inferred earthquake depth. This is a recurring problem in historical earthquake catalogues; a condition that is hard to overcome even for modern earthquakes, and even if a very rapid damage survey is carried out, because the first large shock inevitably causes an increase in the vulnerability whose effects on later shocks are virtually impossible to identify.

The comparison of the attenuation slope calculated using the $R_{J B}$ or using the moving window/variable moving window methodology proposed here shows only modest fluctuations; in fact, they are comparable to the error arising from the uncertainties in the epicentral location. For the 1915 earthquake we found a steepness of 0.044, 0.044 and 0.047 , respectively using the $R_{J B}$ approach, the moving window approach and the variable moving window approach. These steepness fluctuations imply a difference of about $1.5 \mathrm{~km}$ in the expected depth. Given the uncertainty about our knowledge of the source geometry for historical earthquakes and the limited impact of using the $R_{J B}$ distance in the window approach, we decided to recalculate all distances for earthquakes having $M_{w} \geq 6.75$ using the variable moving windows method only, which analyses the MDPs over circular search areas.

In conclusion, using an extended source approach for the largest earthquakes has a minimal influence on the steepness. Conversely, the effect on the $y$-intercept $\left(I_{E}\right)$ is not negligible. The correct way of calculating their magnitude would be using $R_{J B}$ distances, but due to the lack of information on source geometry we use the variable moving windows method and apply a geometric correction to the intercept value. As a result, for 21 earthquakes having $M_{w} \geq 6.75$ (see Table S1) we assumed an extended source with a radius of $R_{e}$. Consequently, the distances of the relevant MDPs were systematically reduced by $R_{e}$, leading to a geometric correction of the regression line and of its intercept: $I_{E}=I_{E}-S * R_{e}$.

Finally, we recalculated the magnitude of these 21 earthquakes using Eq. 5.

\subsection{A method for inferring the depth and magnitude for earthquakes of the CPTI15/DBMI15 catalogue}

We applied our methodology to the pre-1984 earthquakes of the DBMI15 v2.0 catalogue (Locati et al., 2019). We analyzed only pre-1984 events because their parameters were computed from intensity data as their instrumental location is generally unreliable, although there are notable exceptions (see discussion in Rovida et al. (2021)).

We first selected the earthquakes to be analyzed: they must meet all criteria listed in Sect. 3.1 "Data Selection criteria" except for \#6, which we relaxed by reducing the minimum number of MDPs from 60 to 30, based on the conclusions drawn in Sect. 3.5 "Reliability and validation of the depth estimation method". These criteria were passed by 206 out of 2,679 earthquakes (Figure 10 and Table S1), which comprise the analyzed set of this work. Unfortunately, most of the events listed in DBMI15 (80\%) exhibit less than 30 MDPs within the first $55 \mathrm{~km}$ from the epicenter, and therefore had to be discarded. To estimate the depth of the 206 events that were retained we first calculated the steepness of the line that best fits the first $50 \mathrm{~km}$ of the attenuation curve of each event, then we used Eq. 6, which is simply the reverse of Eq. 3:

$D=e^{\frac{0.087-S}{0.018}}$ 


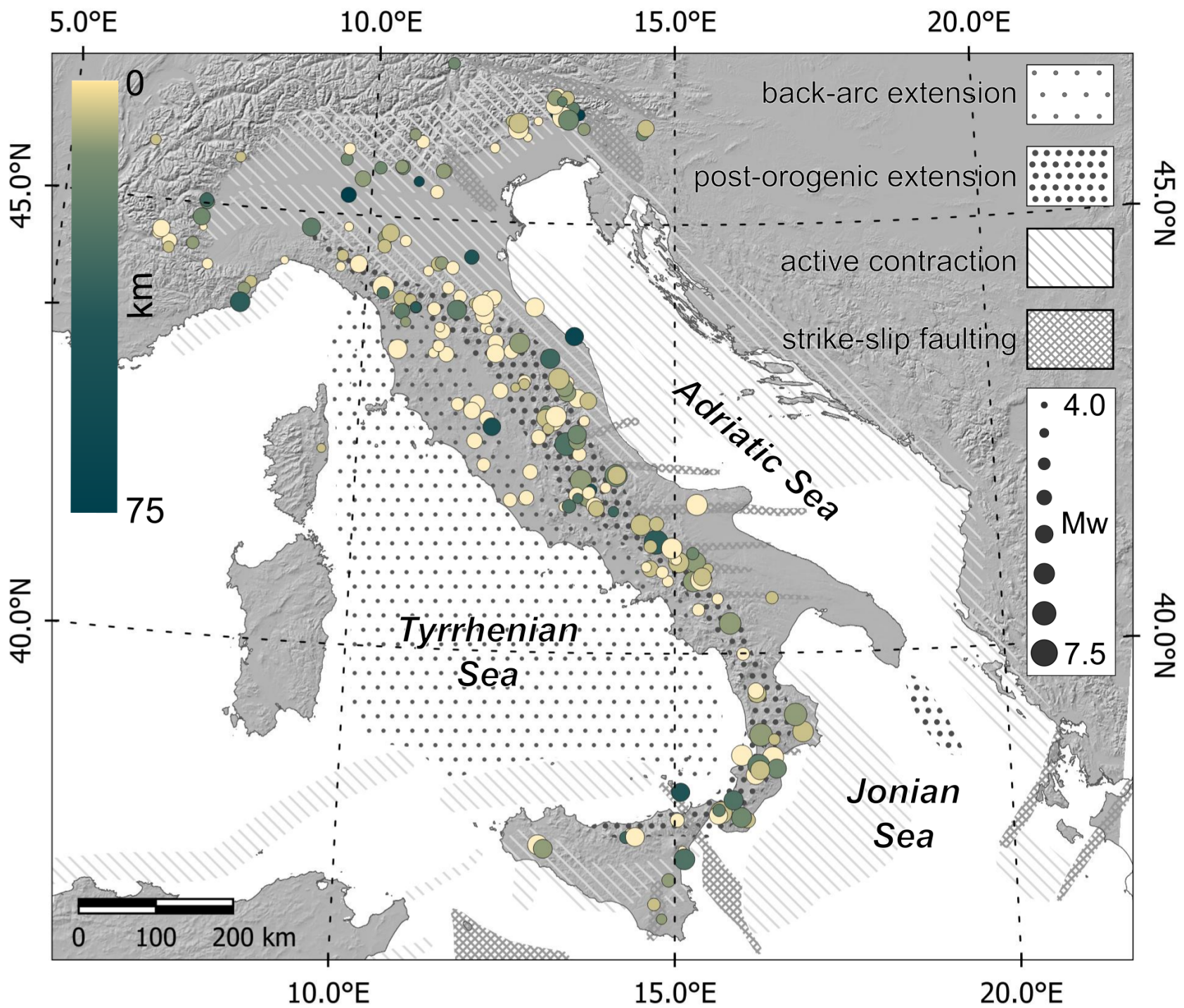

Figure 10. Estimated depth calculated using our approach (colour coded) for the 206 earthquakes of the analyzed set, shown with symbol size scaled with the magnitude calculated in this work.

In Sect. 3.2 we clarified that we can calculate a reliable depth only for events whose $S$ falls in the interval 0.058 to 0.012 (Figure 5), which corresponds to the depth interval 5.0-73.0 km, respectively (Table S1). This implies that an inferred 5.0 $\mathrm{km}$ depth must be intended as $\leq 5.0 \mathrm{~km}$, and similarly, a $73.0 \mathrm{~km}$ depth stands for $\geq 73.0 \mathrm{~km}$. Notice that the uncertainty associated with the inferred depths is determined by the confidence interval shown in Figure 5, and is hence larger for deeper earthquakes. In addition, Eq. 3 and Eq. 6 are affected by the accuracy of the instrumental location of the learning set earth- 
https://doi.org/10.5194/nhess-2022-30

Preprint. Discussion started: 17 February 2022

(c) Author(s) 2022. CC BY 4.0 License.

quakes, on the basis of which the logarithmic curve data are fitted. Furthermore, we must keep in mind that the reliability of the depth determination ultimately depends on the quality of the available macroseismic data.

Once the depth of the 206 selected earthquakes is known, we can estimate their magnitude using Eq 5. All estimated depths and magnitudes are shown in Figure 10 (see Table S1).

\subsection{Reliability of the magnitude estimation method}

As a countercheck we used our method to calculate the depth first (Eq. 6) and then the magnitudes (Eq. 5) of the 42 events of our learning set (Figure 11, Table S2), so as to analyze the departure from the instrumental magnitudes listed in Table 1.

We obtained differences in the range 0.68 to -0.41 magnitude units, respectively, with an average of -0.03 and a mean squared deviation of 0.28 .

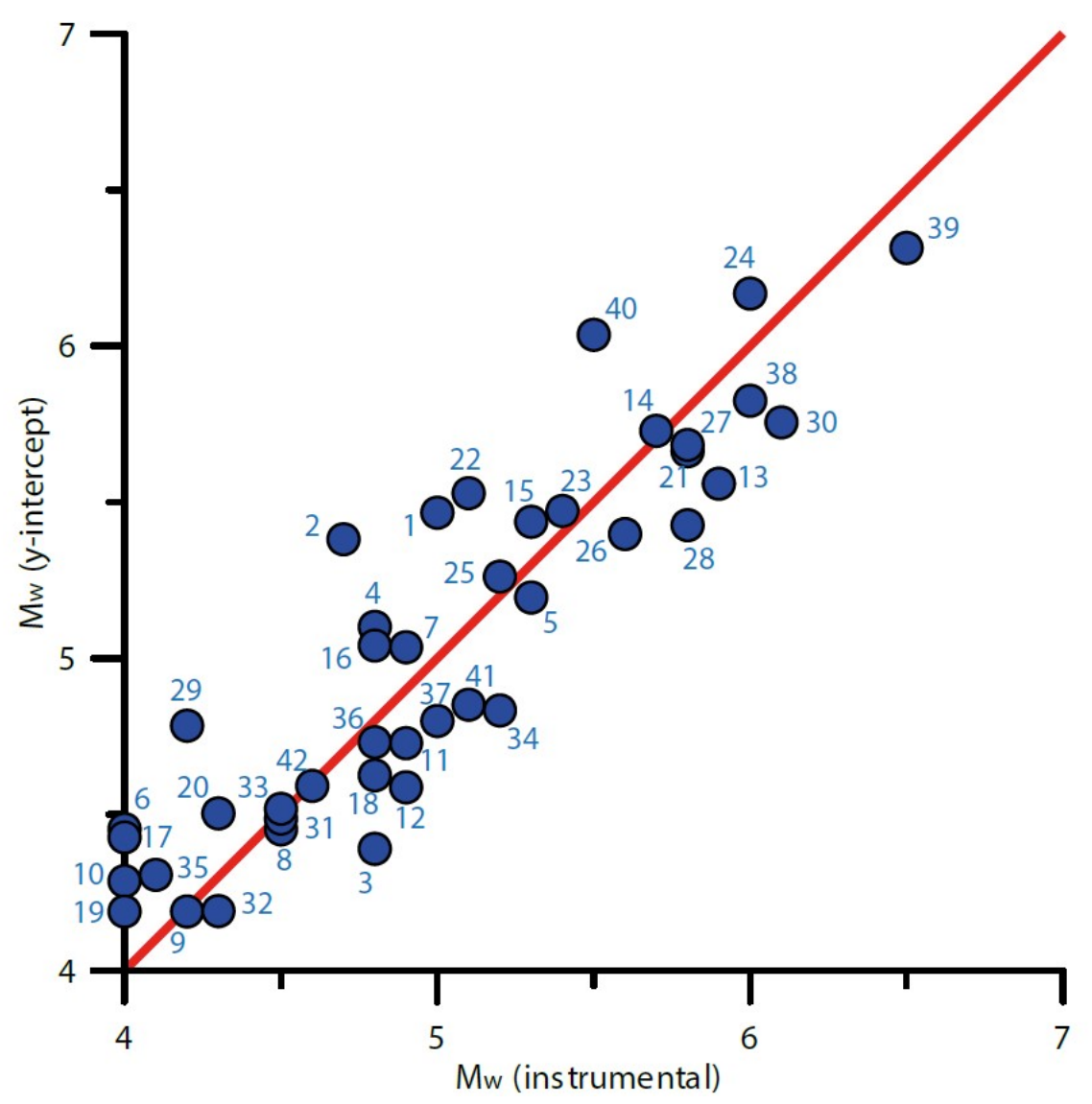

Figure 11. Correlation between the $M_{w}$ calculated with the $y$-intercept approach proposed in this work and the instrumental $M_{w}$ reported in Table 1 (Rovida et al., 2020) for all the events of the learning set. Earthquakes falling above or below the line exhibit a larger (up to +0.61 magnitude units) or smaller (up to -0.41 magnitude units) $M_{w}$, respectively. 
We then compared the macroseismic magnitudes calculated through our method with those calculated through the Boxer method, using the very same intensity dataset from DBMI15. Notice, however, that the parameters of the earthquakes comprising our learning set were computed using also data from other sources, such as HSIT, CFTI5Med etc. (Table 1). Table 2 lists the magnitude of all learning set earthquakes for which the comparison was possible. Notwithstanding the significant differences between the two methods, the mean squared deviations between instrumental magnitudes and those estimated with Boxer and our method are comparable, as they are 0.38 and 0.35 respectively.

We wish to stress once again that the reliability of the magnitude and depth determinations shown in Figure 10 and Table $\mathrm{S} 1$ depends on both the quality of the macroseismic data and the accuracy of the epicentral locations. For completeness of information, Table S1 reports also the full details of the processing for each of the selected events. Some of the results may appear unrealistic, due to inherent uncertainties that are reflected in the determination of the steepness and of the $y$-intercept (as defined in Sect. 3.7): these may include the cumulation of damage from subsequent shocks, unpredictable anomalies in wave propagation, strong source directivity and site amplification effects, all of which may also cause a sizable shift in the epicentral location.

Finally, the reliability of $y$-intercept $M_{w}$ is a function of the accuracy of the estimated depth. For instance, we examined the 13 January 1909, Northern Italy earthquake (https://emidius.mi.ingv.it/ASMI/event/19090113_0045_000), whose macroseismic field is suggestive of a rather deep source. We obtained a depth of $44 \mathrm{~km}$, yielding a $M_{w} 5.5$; should this earthquake be much shallower (e.g. $5 \mathrm{~km}$ ), Eq. 5 would return a substantially smaller $M_{w}(5.1)$.

\subsection{Comparison between $y$-intercept $M_{w}$ and Boxer $M_{w}$}

Before comparing the $M_{w}$ estimates obtained with our approach and those listed in the CPTI15 catalogue we must recall that all $M_{w}$ estimates supplied by this catalogue are inherently hybrid, because the decision to adopt the macroseismic or the instrumental value as 'preferred' is made on a case-by-case basis. To minimize the ambiguities that may arise from these circumstances our analyzed set includes only 206 pre-1984 events that satisfy all our selection criteria; for the vast majority of these events CPTI15 adopted as preferred the intensity-based magnitude (Rovida et al., 2021).

Figure 12 shows a comparison of the magnitude obtained with our methodology with the corresponding magnitude listed in CPTI15 (Table S1). The two sets of estimates are generally consistent, yet on average the magnitudes calculated in the present work show a difference of +0.25 magnitude units. Moreover, Vannucci et al. (2021) stated that the magnitudes of all pre-instrumental earthquakes in CPTI15 might be overestimated by $0.1-0.2$ units due to differences in the response of pre1960 seismographs relative to the response of more recent and better calibrated electromagnetic sensors. If this is the case, the difference between our estimates and the CPTI15 estimates summarized in Figure 12 would be even larger.

The calculated $M_{w}$ may also vary if we consider macroseismic intensities assigned using the MCS or the EMS scale; according to Vannucci et al. (2021), using one or the other may cause differences in the macroseismic location. It is important to be aware that the calculation of $M_{w}$ from macroseismic data is controlled by a number of variables whose relative weight is critical: assigning proper weights, however, is not an easy task, regardless of the quality of the data and of the reliability of the adopted algorithm. 


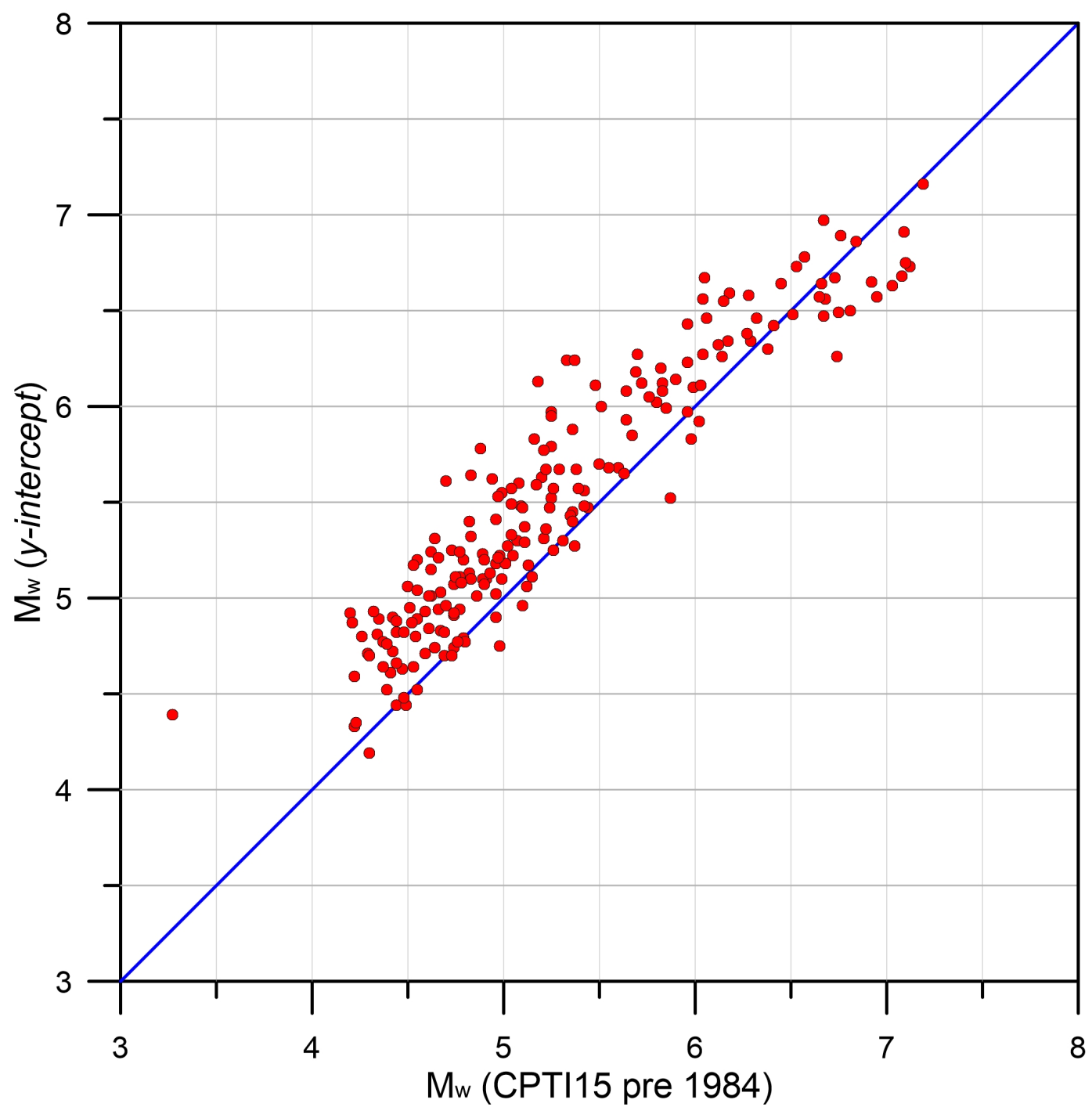

Figure 12. Correlation between the $M_{w}$ calculated with the $y$-intercept approach proposed in this work and the $M_{w}$ reported in the latest version of the pre-1984 CPTI15 catalogue (Rovida et al., 2021) for all the events that occurred before 1984. Earthquakes falling above or below the blue line exhibit a larger (up to +1.12 magnitude units) or smaller (up to -0.48 magnitude units) $M_{w}$, respectively. The global average is +0.25 magnitude units.

The +0.25 magnitude unit difference we found implies that on average our seismic moments are 2.3 times larger than those obtained with conventional methods; a conclusion that may have strong implications for the assessment of seismic hazard. 


\section{Conclusions}

In this study we proposed a two-step procedure for deriving the depth and magnitude of Italian earthquakes from official, publicly accessible macroseismic intensity data, i.e. from the "classic" DBMI15 database and from the innovative, web-based HSIT dataset. The main merit of the proposed methodology is its objectivity and ease of application.

Web-based macroseismic systems allow a large amount of data to be collected through crowd-sourcing, and are often the only available source of information concerning the effects of low-to-medium magnitude earthquakes. In fact, HSIT data were critical to performing this work because - especially for deeper earthquakes ( $>30 \mathrm{~km})$ - they were almost always the only available observations.

We proved that the initial $50 \mathrm{~km}$ of the attenuation curve contain all the elements needed to retrieve not only the depth, but also the magnitude of any given earthquake.

The first step of our procedure involves the calculation of the earthquake depth (Eq. 6). Based on our experimental observations we have shown that the steepness of the attenuation curve in the first $50 \mathrm{~km}$ from the epicenter is independent of magnitude and is solely a function of the source depth. We also found that the steepness does not vary much as a result of any regional differences in the propagation properties. This finding implies that these properties do not change much countrywide, despite the well-known complexity of Italian geodynamics and despite the ensuing geological heterogeneity, and that our new relations are valid for the whole Italian territory (Figure 5).

The second step involves estimating the magnitude using an empirical law obtained from a regression function that relates the expected epicentral intensity to the depth and magnitude of the 42 earthquakes comprising our learning set (Eq. 5).

We applied this methodology to 206 earthquakes from the CPTI15 catalogue, after removing all events whose macroseismic field is too sparse or too inhomogeneous to return reliable results.

Our approach allowed us to verify that the inferred depth is consistent with the presumed earthquake-causative tectonic structures, and is essential to obtain a well-calibrated magnitude value. We contend that the new methodology may be crucial for mitigating the trade-off between earthquake depth and magnitude; this is a pre-condition for calculating reliable depth estimates — and hence reliable magnitudes — for earthquakes of the pre-instrumental era.

The historical record is the main pillar of any seismic hazard analysis, conducted at any scale and using any approach. We maintain that the revised framework discussed in this work may ultimately serve for exploiting more systematically the enormous potential of historical earthquake data, and ultimately for providing inherently more reliable input data for seismic hazard assessment.

Code availability. Code cannot be shared at this stage

Data availability. This work used only published or public domain datasets 
https://doi.org/10.5194/nhess-2022-30

Preprint. Discussion started: 17 February 2022

(c) Author(s) 2022. CC BY 4.0 License.

(c) (i)

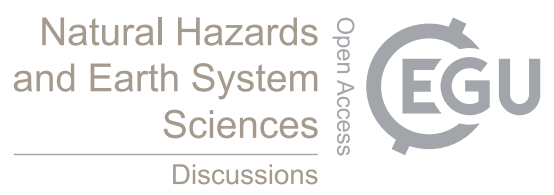

Author contributions. P.S. conceived the work and wrote the initial draft of the paper, P.B., P.T., P.V. and G.V. contributed to delineating the structure of the paper. P.B., P.V. and G.V. provided information on the seismotectonic background, along with the associated interpretations,

475 P.S. and R.V. analyzed the macroseismic data and R.V. implemented the algorithms in the R language. P.T. tested the method through the use of synthetic data. V.D.R. statistically evaluated the effects of the finite seismic sources. P.S. and G.V. did most of the writing. All authors discussed the results and contributed to the final version of the paper.

Competing interests. The authors declare that they have no conflict of interest.

Acknowledgements. We thank Franco Mele, Mario Locati, Graziano Ferrari, Livio Sirovich and Franco Pettenati for suggestions and for providing valuable insight during the early stages of this work. 


\section{References}

Albarello, D. and D'Amico, V.: Attenuation relationship of macroseismic intensity in Italy for probabilistic seismic hazard assessment, Bollettino di Geofisica Teorica ed Applicata, 45, 271-284, 2004.

Ambraseys, N.: Intensity-attenuation and magnitude-intensity relationships for northwest European earthquakes, Earthquake engineering \& structural dynamics, 13, 733-778, 1985.

Bakun, W., Johnston, A., and Hopper, M.: Estimating locations and magnitudes of earthquakes in eastern North America from modified Mercalli intensities, Bulletin of the Seismological Society of America, 93, 190-202, https://doi.org/10.1785/0120020087, 2003.

Bakun, W. H. and Scotti, O.: Regional intensity attenuation models for France and the estimation of magnitude and location of historical earthquakes, Geophysical Journal International, 164, 596-610, https://doi.org/10.1111/j.1365-246X.2005.02808.x, 2006.

Bakun, W. u. and Wentworth, C.: Estimating earthquake location and magnitude from seismic intensity data, Bulletin of the Seismological Society of America, 87, 1502-1521, https://doi.org/10.1785/BSSA0870061502, 1997.

Basili, R., Valensise, G., Vannoli, P., Burrato, P., Fracassi, U., Mariano, S., Tiberti, M. M., and Boschi, E.: The Database of Individual Seismogenic Sources (DISS), version 3: Summarizing 20 years of research on Italy's earthquake geology, Tectonophysics, 453, 20-43, https://doi.org/https://doi.org/10.1016/j.tecto.2007.04.014, earthquake Geology: Methods and Applications, 2008.

Blake, A.: On the estimation of focal depth from macroseismic data, Bulletin of the seismological society of America, 31, 225-231, https://doi.org/10.1785/BSSA0310030225, 1941.

Bonini, L., Basili, R., Burrato, P., Cannelli, V., Fracassi, U., Maesano, F. E., Melini, D., Tarabusi, G., Tiberti, M. M., Vannoli, P., and Valensise, G.: Testing Different Tectonic Models for the Source of the Mw 6.5, 30 October 2016, Norcia Earthquake (Central Italy): A Youthful Normal Fault, or Negative Inversion of an Old Thrust?, Tectonics, 38, 990-1017, https://doi.org/https://doi.org/10.1029/2018TC005185, 2019.

Boschi, E., Ferrari, G., Gasperini, P., Guidoboni, E., Smriglio, G., and Valensise, G.: Catalogo dei forti terremoti in Italia dal 461 a.C. al 1980, CDROM, 1995.

Boschi, E., Guidoboni, E., Ferrari, G., Mariotti, D., Valensise, G., and Gasperini, P.: Catalogue of Strong Italian Earthquakes from 461 BC to 1997 (Appendix to volume $43 \mathrm{~N}^{\circ}$ 4, 2000), Annals of Geophysics, 43, 2000.

Bragato, P., Sugan, M., Augliera, P., Massa, M., Vuan, A., and Saraò, A.: Moho reflection effects in the Po Plain (northern Italy) observed from instrumental and intensity data, Bulletin of the Seismological Society of America, 101, 2142-2152, https://doi.org/10.1785/0120100257, 2011.

Burton, P., McGonigle, R., Neilson, G., and Musson, R. M.: Macroseismic focal depth and intensity attenuation for British earthquakes, in: Earthquake engineering in Britain, pp. 91-109, Thomas Telford Publishing, 1985.

Buttinelli, M., Petracchini, L., Maesano, F. E., D’Ambrogi, C., Scrocca, D., Marino, M., Capotorti, F., Bigi, S., Cavinato, G. P., Mariucci, M. T., Montone, P., and Di Bucci, D.: The impact of structural complexity, fault segmentation, and reactivation on seismotectonics: Constraints from the upper crust of the 2016-2017 Central Italy seismic sequence area, Tectonophysics, 810, 228 861, https://doi.org/10.1016/j.tecto.2021.228861, 2021.

Castello, B., Selvaggi, G., Chiarabba, C., and Amato, A.: Catalogo della sismicità italiana (CSI) 1981-2002, https://doi.org/10.13127/CSI.1.1, 2006.

Cattaneo, M., Frapiccini, M., Ladina, C., Marzorati, S., and Monachesi, G.: A mixed automatic-manual seismic catalog for Central-Eastern Italy: analysis of homogeneity, Annals of Geophysics, https://doi.org/10.4401/ag-7333, 2017. 
Cauzzi, C. and Faccioli, E.: Broadband (0.05 to $20 \mathrm{~s})$ prediction of displacement response spectra based on worldwide digital records, Journal of Seismology, 12, 453-475, https://doi.org/10.1007/s10950-008-9098-y, 2008.

Chiarabba, C. and De Gori, P.: The seismogenic thickness in Italy: constraints on potential magnitude and seismic hazard, Terra Nova, 28, 402-408, https://doi.org/10.1111/ter.12233, 2016.

Chiarabba, C., De Gori, P., and Speranza, F.: The southern Tyrrhenian subduction zone: Deep geometry, magmatism and Plio-Pleistocene evolution, Earth and Planetary Science Letters, 268, 408-423, https://doi.org/https://doi.org/10.1016/j.eps1.2008.01.036, 2008.

Chiaraluce, L., Valoroso, L., Piccinini, D., Di Stefano, R., and De Gori, P.: The anatomy of the 2009 L'Aquila normal fault system (central Italy) imaged by high resolution foreshock and aftershock locations, Journal of Geophysical Research: Solid Earth, 116, https://doi.org/https://doi.org/10.1029/2011JB008352, 2011.

De Luca, G., Cattaneo, M., Monachesi, G., and Amato, A.: Seismicity in Central and Northern Apennines integrating the Italian national and regional networks, Tectonophysics, 476, 121-135, https://doi.org/https://doi.org/10.1016/j.tecto.2008.11.032, ten years after the UmbriaMarche earthquake, Central Italy, 2009.

530 De Martini, P. M., Alessandro Pino, N., Valensise, G., and Mazza, S.: Geodetic and seismologic evidence for slip variability along a blind normal fault in the Umbria-Marche 1997-1998 earthquakes (central Italy), Geophysical Journal International, 155, 819-829, https://doi.org/10.1111/j.1365-246X.2003.02049.x, 2003.

De Rubeis, V., Sbarra, P., and Tosi, P.: Regional macroseismic field and intensity residuals of the August 24, 2016, Mw=6.0 central Italy earthquake, Annals of Geophysics, 59, https://doi.org/10.4401/ag-7217, 2016.

De Rubeis, V., Sbarra, P., Tosi, P., and Sorrentino, D.: Hai Sentito Il Terremoto (HSIT) - Macroseismic intensity database 2007-2018, version 1, https://doi.org/10.13127/HSIT/I.1, 2019.

Di Bona, M.: A local magnitude scale for crustal earthquakes in Italy, Bulletin of the Seismological Society of America, 106, 242-258, https://doi.org/10.1785/0120150155, 2016.

Di Bucci, D., Burrato, P., Vannoli, P., and Valensise, G.: Tectonic evidence for the ongoing Africa-Eurasia convergence in central Mediterranean foreland areas: A journey among long-lived shear zones, large earthquakes, and elusive fault motions, Journal of Geophysical Research: Solid Earth, 115, https://doi.org/https://doi.org/10.1029/2009JB006480, 2010.

Di Luccio, F., Piscini, A., Pino, N. A., and Ventura, G.: Reactivation of deep faults beneath Southern Apennines: evidence from the 1990-1991 Potenza seismic sequences, Terra Nova, 17, 586-590, https://doi.org/https://doi.org/10.1111/j.1365-3121.2005.00653.x, 2005.

DISS Working Group: Database of Individual Seismogenic Sources (DISS), version 3.3.0: A compilation of potential sources for earthquakes larger than M 5.5 in Italy and surrounding areas., https://doi.org/10.13127/DISS3.3.0, 2021.

Douglas, J.: Earthquake ground motion estimation using strong-motion records: a review of equations for the estimation of peak ground acceleration and response spectral ordinates, Earth-Science Reviews, 61, 43-104, https://doi.org/https://doi.org/10.1016/S00128252(02)00112-5, 2003.

Douglas, J.: Ground motion prediction equations 1964-2021, http://www.gmpe.org.uk, 2021.

550 Faenza, L. and Michelini, A.: Regression analysis of MCS intensity and ground motion parameters in Italy and its application in ShakeMap, Geophysical Journal International, 180, 1138-1152, https://doi.org/10.1111/j.1365-246X.2009.04467.x, 2010.

Fah, D. and Panza, G. F.: Realistic modelling of observed seismic motion in compIex sedimentary basins, Annals of Geophysics, 37, https://doi.org/10.4401/ag-4141, 1994. 
Frepoli, A., Cimini, G., De Gori, P., De Luca, G., Marchetti, A., Monna, S., Montuori, C., and Pagliuca, N.: Seismic sequences and swarms in the Latium-Abruzzo-Molise Apennines (central Italy): New observations and analysis from a dense monitoring of the recent activity, Tectonophysics, 712-713, 312-329, https://doi.org/https://doi.org/10.1016/j.tecto.2017.05.026, 2017.

Galli, P., Camassi, R., Castenetto, S., Lucantoni, A., Molin, D., Naso, G., Peronace, E., Bernardini, F., Cavaliere, A., Ercolani, E., Castelli, V., Salimbeni, S., Tripone, D., Vannucci, G., Arcoraci, L., Berardi, M., Castellano, C., Del Mese, S., Graziani, L., Leschiutta, I., Massucci, A., Maramai, A., Rossi, A., Tertulliani, A., Vecchi, M., Azzaro, R., D’Amico, S., Ferrari, F., Platania, P. R., Scarfî, L., Tuvè, T., Zuccarello, L., Carlino, S., Marturano, A., Albini, P., Gómez Capera, A. A., Stucchi, M., Locati, M., Meroni, F., Pessina, V., Piccarreda, C., Rovida, A., Buffarini, G., Paolini, S., Verrubbi, V., Mucciarelli, M., Gallipoli, M., Barbano, M. S., and Cecić, I.: Rapporto sugli effetti del terremoto aquilano del 6 aprile 2009, https://doi.org/10.13127/QUEST/20090406, 2009.

Gasparini, C., Conte, S., and Vannucci, C.: Bollettino macrosismico 2001-2005, 2011.

Gasperini, P.: The Attenuation of Seismic Intensity in Italy: A Bilinear Shape Indicates the Dominance of Deep Phases at Epicentral Distances

Gasperini, P., Bernardini, F., Valensise, G., and Boschi, E.: Defining seismogenic sources from historical earthquake felt reports, Bulletin of the Seismological Society of America, 89, 94-110, https://doi.org/10.1785/BSSA0890010094, 1999.

Govoni, A., Marchetti, A., De Gori, P., Di Bona, M., Lucente, F. P., Improta, L., Chiarabba, C., Nardi, A., Margheriti, L., Agostinetti, N. P., Di Giovambattista, R., Latorre, D., Anselmi, M., Ciaccio, M. G., Moretti, M., Castellano, C., and Piccinini, D.: The 2012 Emilia seismic sequence (Northern Italy): Imaging the thrust fault system by accurate aftershock location, Tectonophysics, 622, 44-55, https://doi.org/https://doi.org/10.1016/j.tecto.2014.02.013, 2014.

Graziani, L., Del Mese, S., Tertulliani, A., Arcoraci, L., Maramai, A., and Rossi, A.: Investigation on damage progression during the 20162017 seismic sequence in Central Italy using the European Macroseismic Scale (EMS-98), Bulletin of Earthquake Engineering, 17, 5535-5558, https://doi.org/10.1007/s10518-019-00645-w, 2019.

Grimaz, S. and Malisan, P.: How could cumulative damage affect the macroseismic assessment?, Bulletin of Earthquake Engineering, 15, 2465-2481, https://doi.org/10.1007/s10518-016-0016-3, 2017.

Grünthal, G.: European macroseismic scale 1998, Tech. rep., European Seismological Commission (ESC), 1998.

Guidoboni, E. and Ebel, J.: Earthquakes and Tsunamis in the Past. A Guide to Techniques in Historical Seismology, Cambridge University Press, 2009.

580 Guidoboni, E., Ferrari, G., Tarabusi, G., Sgattoni, G., Comastri, A., Mariotti, D., Ciuccarelli, C., Bianchi, M. G., and Valensise, G.: CFTI5Med, the new release of the catalogue of strong earthquakes in Italy and in the Mediterranean area, Scientific Data, 6, 80, https://doi.org/10.1038/s41597-019-0091-9, 2019.

Gutdeutsch, R., Kaiser, D., and Jentzsch, G.: Estimation of earthquake magnitudes from epicentral intensities and other focal parameters in Central and Southern Europe, Geophysical Journal International, 151, 824-834, https://doi.org/10.1046/j.1365-246X.2002.01804.x, 2002.

ISIDe Working Group: Italian Seismological Instrumental and Parametric Database (ISIDe), https://doi.org/10.13127/ISIDE, 2007.

Jánosi, I.: Makroszeizmikus rengések feldolgozása a Cancani-féle egyenlet alapján, Az, pp. 77-82, 1906.

Joyner, W. B. and Boore, D. M.: Peak horizontal acceleration and velocity from strong-motion records including records from the 1979 imperial valley, California, earthquake, Bulletin of the Seismological Society of America, 71, 2011-2038, 1981.

Kövesligethy, R. v.: Seismischer Stärkegrad und Intensität der Beben, Gerlands Beitr. Geoph., Bd, 8, 24-103, 1907.

590 Levret, A., Cushing, M., Peyridieu, G., and de protection et de sûreté nucléaire (France), I.: Étude des caractéristiques de séismes historiques en France: Atlas de 140 cartes macroscopiques. Volume I, Institut de protection et de sûreté nucléaire, 1996. 
Locati, M., Camassi, R., Rovida, A., Ercolani, E., Bernardini, F., Castelli, V., Caracciolo, C. H., Tertulliani, A., Rossi, A., Azzaro, R., D’Amico, S., and Antonucci, A.: Database Macrosismico Italiano (DBMI15), versione 2.0, https://doi.org/10.13127/DBMI/DBMI15.2, 2019.

Lolli, B., Gasperini, P., Mele, F. M., and Vannucci, G.: Recalibration of the Distance Correction Term for Local Magnitude (ML) Computations in Italy, Seismological Research Letters, 86, 1383-1392, https://doi.org/10.1785/0220150020, 2015.

Maesano, F. E., Tiberti, M. M., and Basili, R.: The Calabrian Arc: three-dimensional modelling of the subduction interface, Scientific reports, 7, 1-15, 2017.

Maesano, F. E., Tiberti, M. M., and Basili, R.: Deformation and Fault Propagation at the Lateral Termination of a Subduction Zone: The Alfeo Fault System in the Calabrian Arc, Southern Italy, Frontiers in Earth Science, 8, https://doi.org/10.3389/feart.2020.00107, 2020.

Mariotti, G. and Doglioni, C.: The dip of the foreland monocline in the Alps and Apennines, Earth and Planetary Science Letters, 181, 191-202, https://doi.org/https://doi.org/10.1016/S0012-821X(00)00192-8, 2000.

Mariucci, M. T. and Montone, P.: Database of Italian present-day stress indicators, IPSI 1.4, Scientific data, 7, 1-11, https://doi.org/10.1038/s41597-020-00640-w, 2020.

Masi, A., Chiauzzi, L., Nicodemo, G., and Manfredi, V.: Correlations between macroseismic intensity estimations and ground motion measures of seismic events, Bulletin of Earthquake Engineering, 18, 1899-1932, https://doi.org/10.1007/s10518-019-00782-2, 2020.

Mele, G., Rovelli, A., Seber, D., and Barazangi, M.: Shear wave attenuation in the lithosphere beneath Italy and surrounding regions: Tectonic implications, Journal of Geophysical Research: Solid Earth, 102, 11 863-11 875, https://doi.org/https://doi.org/10.1029/97JB00262, 1997.

Michele, M., Chiaraluce, L., Di Stefano, R., and Waldhauser, F.: Fine-Scale Structure of the $2016-2017$ Central Italy Seismic Sequence From Data Recorded at the Italian National Network, Journal of Geophysical Research: Solid Earth, 125, https://doi.org/https://doi.org/10.1029/2019JB018440, 2020.

Musson, R. M.: Determination of parameters for historical British earthquakes, Annals of Geophysics, 39, https://doi.org/10.4401/ag-4035, 1996.

Musson, R. M. W.: Intensity attenuation in the UK, Journal of Seismology, 9, 73-86, https://doi.org/10.1007/s10950-005-2979-4, 2005.

Olivieri, M. and Ekström, G.: Rupture depths and source processes of the 1997-1998 earthquake sequence in central Italy, Bulletin of the Seismological Society of America, 89, 305-310, https://doi.org/10.1785/BSSA0890010305, 1999.

Pasolini, C., Albarello, D., Gasperini, P., D’Amico, V., and Lolli, B.: The Attenuation of Seismic Intensity in Italy, Part II: Modeling and Validation, Bulletin of the Seismological Society of America, 98, 692-708, https://doi.org/10.1785/0120070021, 2008.

Piccinini, D., Chiarabba, C., Augliera, P., and (M.E.G.), M. E. G.: Compression along the northern Apennines? Evidence from the Mw 5.3 Monghidoro earthquake, Terra Nova, 18, 89-94, https://doi.org/https://doi.org/10.1111/j.1365-3121.2005.00667.x, 2006.

Pondrelli, S., Visini, F., Rovida, A., D’Amico, V., Pace, B., and Meletti, C.: Style of faulting of expected earthquakes in Italy as an input for seismic hazard modeling, Natural Hazards and Earth System Sciences, 20, 3577-3592, https://doi.org/10.5194/nhess-20-3577-2020, 2020.

Provost, L. and Scotti, O.: QUake-MD: Open-Source Code to Quantify Uncertainties in Magnitude-Depth Estimates of Earthquakes from

Rosenbaum, G. and Piana Agostinetti, N.: Crustal and upper mantle responses to lithospheric segmentation in the northern Apennines, Tectonics, 34, 648-661, https://doi.org/10.1002/2013TC003498, 2015. 
Rossi, A., Tertulliani, A., Azzaro, R., Graziani, L., Rovida, A., Maramai, A., Pessina, V., Hailemikael, S., Buffarini, G., Bernardini, F., et al.: The 2016-2017 earthquake sequence in Central Italy: macroseismic survey and damage scenario through the EMS-98 intensity assessment, Bulletin of Earthquake Engineering, 17, 2407-2431, https://doi.org/10.1007/s10518-019-00556-w, 2019.

Rovida, A., Locati, M., Camassi, R., Lolli, B., and Gasperini, P.: Catalogo Parametrico dei Terremoti Italiani (CPTI15), versione 2.0, https://doi.org/10.13127/CPTI/CPTI15.2, 2019.

Rovida, A., Locati, M., Camassi, R., Lolli, B., and Gasperini, P.: The Italian earthquake catalogue CPTI15, Bulletin of Earthquake Engineering, pp. 1-32, 2020.

Rovida, A., Locati, M., Camassi, R., Lolli, B., Gasperini, P., and Antonucci, A.: Catalogo Parametrico dei Terremoti Italiani (CPTI15), versione 3.0, https://doi.org/10.13127/CPTI/CPTI15.3, 2021.

Sbarra, P., Burrato, P., Tosi, P., Vannoli, P., e Rubeis, V., and Valensise, G.: Inferring the depth of pre-instrumental earthquakes from macroseismic intensity data: a case-history from Northern Italy, Scientific reports, 9, 1-13, https://doi.org/10.1038/s41598-019-51966-4, 2019a.

Sbarra, P., Tosi, P., De Rubeis, V., and Sorrentino, D.: HSIT macroseismic questionnaire database 2007-2018, version 1, https://doi.org/10.13127/HSIT/Q.1, 2019b.

Scardia, G., Festa, A., Monegato, G., Pini, R., Rogledi, S., Tremolada, F., and Galadini, F.: Evidence for late Alpine tectonics in the Lake Garda area (northern Italy) and seismogenic implications, GSA Bulletin, 127, 113-130, https://doi.org/10.1130/B30990.1, 2015.

Scrocca, D., Carminati, E., Doglioni, C., and Marcantoni, D.: Slab Retreat and Active Shortening along the Central-Northern Apennines, in: Thrust Belts and Foreland Basins, edited by Lacombe, O., Roure, F., Lavé, J., and Vergés, J., pp. 471-487, Springer Berlin Heidelberg, Berlin, Heidelberg, 2007.

Selvaggi, G., Ferulano, F., Di Bona, M., Frepoli, A., Azzara, R., Basili, A., Chiarabba, C., Ciaccio, M., Di Luccio, F., Lucente, F., et al.: The MW 5.4 Reggio Emilia 1996 earthquake: active compressional tectonics in the Po Plain, Italy, Geophysical Journal International, 144, 1-13, 2001.

Sirovich, L., Pettenati, F., and Cavallini, F.: Intensity-based source inversion of the destructive earthquake of 1695 in the southern Apennines, Italy, Journal of Geophysical Research: Solid Earth, 118, 6241-6257, https://doi.org/10.1002/2013JB010245, 2013.

Sponheuer, W.: Methoden zur Herdtiefenbestimmung in der Makroseismik, Freiberger Forschungsh, Freiberger Forschungshefte, C88, 1960.

Tertulliani, A. and Azzaro, R.: QUEST - Rilievo macrosismico in EMS98 per il terremoto di Amatrice del 24 agosto 2016 , https://doi.org/10.5281/zenodo.160707, 2016.

Tertulliani, A. and Azzaro, R.: QUEST - Rilievo macrosismico in EMS98 per la sequenza sismica in Italia Centrale: aggiornamento dopo il 18 gennaio 2017, https://doi.org/10.5281/zenodo.556929, 2017.

Tertulliani, A., Arcoraci, L., Berardi, M., Bernardini, F., Brizuela, B., Castellano, C., Del Mese, S., Ercolani, E., Graziani, L., Maramai, A., Rossi, A., Sbarra, M., and Vecchi, M.: The Emilia 2012 sequence: a macroseismic survey, Annals of Geophysics, https://doi.org/10.4401/ag-6140, 2012.

Tosi, P., De Rubeis, V., Sbarra, P., and Sorrentino, D.: Hai Sentito Il Terremoto (HSIT), https://doi.org/10.13127/HSIT, 2007.

660 Tosi, P., Sbarra, P., De Rubeis, V., and Ferrari, C.: Macroseismic intensity assessment method for web questionnaires, Seismological Research Letters, 86, 985-990, 2015.

Traversa, P., Baumont, D., Manchuel, K., Nayman, E., and Durouchoux, C.: Exploration tree approach to estimate historical earthquakes Mw and depth, test cases from the French past seismicity, Bulletin of Earthquake Engineering, 16, 2169-2193, https://doi.org/10.1007/s10518017-0178-7, 2018. 
https://doi.org/10.5194/nhess-2022-30

Preprint. Discussion started: 17 February 2022

(c) Author(s) 2022. CC BY 4.0 License.

(c) (1)

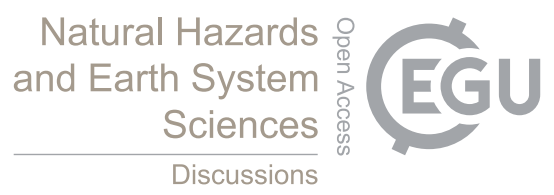

665 Valensise, G., Vannoli, P., Burrato, P., and Fracassi, U.: From Historical Seismology to seismogenic source models, 20 years on: Excerpts from the Italian experience, Tectonophysics, 774, 228 189, https://doi.org/10.1016/j.tecto.2019.228189, 2020.

Vallée, M. and Di Luccio, F.: Source analysis of the 2002 Molise, southern Italy, twin earthquakes (10/31 and 11/01), Geophysical Research Letters, 32, https://doi.org/10.1029/2005GL022687, 2005.

Vannoli, P., Burrato, P., and Valensise, G.: The seismotectonics of the Po Plain (northern Italy): Tectonic diversity in a blind faulting domain, Pure and Applied Geophysics, 172, 1105-1142, https://doi.org/10.1007/s00024-014-0873-0, 2015.

Vannoli, P., Martinelli, G., and Valensise, G.: The Seismotectonic Significance of Geofluids in Italy, Frontiers in Earth Science, 9, https://doi.org/10.3389/feart.2021.579390, 2021.

Vannucci, G., Lolli, B., and Gasperini, P.: Inhomogeneity of Macroseismic Intensities in Italy and Consequences for Macroseismic Magnitude Estimation, Seismological Research Letters, 92, 2234-2244, https://doi.org/10.1785/0220200273, 2021.

675 Wells, D. L. and Coppersmith, K. J.: New Empirical Relationships among Magnitude, Rupture Length, Rupture Width, Rupture Area, and Surface Displacement, Bulletin of the Seismological Society of America, 84, 974-1002, https://doi.org/10.1785/BSSA0840040974, 1994.

Zampieri, D., Vannoli, P., and Burrato, P.: Geodynamic and seismotectonic model of a long-lived transverse structure: The Schio-Vicenza Fault System (NE Italy), Solid Earth, 12, 1967-1986, https://doi.org/10.5194/se-12-1967-2021, 2021. 
https://doi.org/10.5194/nhess-2022-30

Preprint. Discussion started: 17 February 2022

(c) Author(s) 2022. CC BY 4.0 License.
Natural Hazards and Earth System Sciences

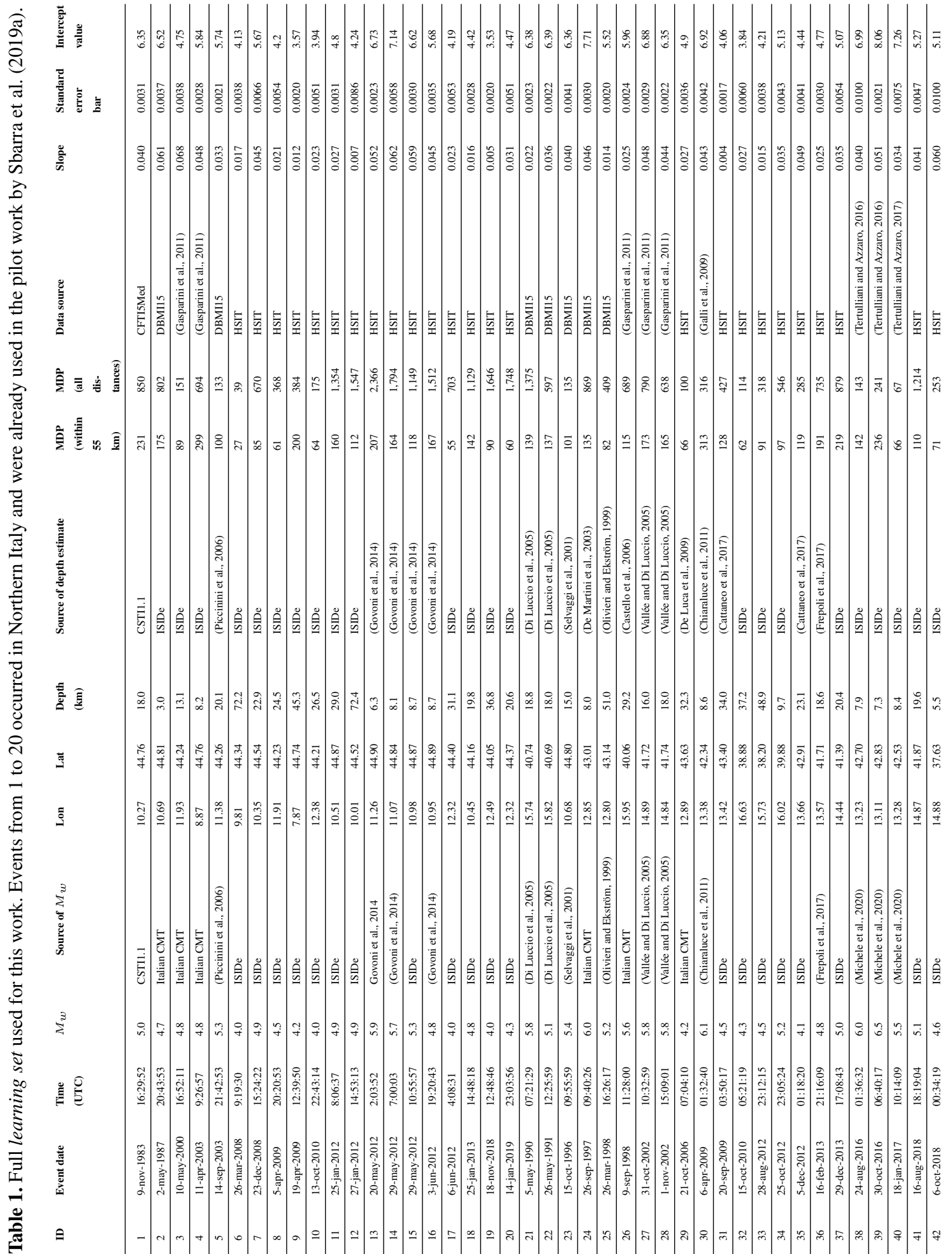


Table 2. Comparison of $M_{w}$ estimates. The source of $M_{w}$ (Boxer code) is the CPTI15 catalogue, v2.0 (Rovida et al., 2019), with the only exception of the last three events, whose $M_{w}$ is from Rossi et al. (2019). The $M_{w}$ (y-intercept) is from this work.

$\begin{array}{cccccc}\text { Event date } & \text { Time UTC } & \begin{array}{c}M_{w} \\ \text { (instrumental) }\end{array} & \begin{array}{c}M_{w} \\ \text { (y-intercept- } \\ \text { This work) }\end{array} & \begin{array}{c}M_{w} \\ \text { (Boxer code) }\end{array} & \text { Source of instrumental } M_{w} \\ \text { 9-Nov-1983 } & 16: 29: 52 & 5.0 & 5.49 & 5.14 & \text { CSTI1.1 } \\ \text { 5-May-1987 } & 20: 43: 53 & 4.7 & 5.42 & 4.91 & \text { Italian CMT } \\ \text { 26-May-1991 } & 12: 25: 59 & 5.1 & 5.52 & 5.22 & \text { Di Luccio et al., 2005 } \\ \text { 15-Oct-1996 } & 09: 55: 59 & 5.4 & 5.49 & 5.19 & \text { Selvaggi et al., 2001 } \\ \text { 26-Sep-1997 } & 09: 40: 26 & 6.0 & 6.17 & 5.89 & \text { Italian CMT } \\ \text { 10-May-2000 } & 16: 52: 11 & 4.8 & 4.4 & 4.4 & \text { Italian CMT } \\ \text { 1-Nov-2002 } & 15: 09: 01 & 5.8 & 5.43 & 5.21 & \text { Vallee and Di Luccio, 2005 } \\ \text { 31-Oct-2002 } & 10: 32: 59 & 5.8 & 5.68 & 5.33 & \text { Vallee and Di Luccio, 2005 } \\ \text { 14-Sep-2003 } & 21: 42: 53 & 5.3 & 5.19 & 4.83 & \text { Piccinini et al., 2006 } \\ \text { 6-Apr-2009 } & 01: 32: 40 & 6.1 & 5.75 & 6.19 & \text { Chiaraluce et al., 2011 } \\ \text { 20-May-2012 } & 02: 03: 52 & 5.9 & 5.56 & 5.15 & \text { Govoni et al., 2014 } \\ \text { 29-May-2012 } & 07: 00: 03 & 5.7 & 5.73 & 5.43 & \text { Govoni et al., 2014 } \\ \text { 24-Aug-2016 } & 01: 36: 32 & 6.0 & 5.82 & 6.46 & \text { Michele et al., 2020 } \\ \text { 30-Oct-2016 } & 06: 40: 17 & 6.5 & 6.31 & 7.00 & \text { Michele et al., 2020 } \\ \text { 18-Jan-2017 } & 10: 14: 09 & 5.5 & 6.03 & 5.60 & \text { Michele et al., 2020 }\end{array}$

